فاعلية برنامج إرثاد باللعب لخفض إضطراب الصمت الإختيارى عند الأطفال

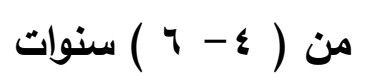

إعداد

د. نجلاء محمد رويي صوفي'

\title{
ملخص الاراسية
}

استهافت الدراسة التعرف على مدى فاعلية برنامج إرشاد باللعب لخفض حدة إضطراب الصمت

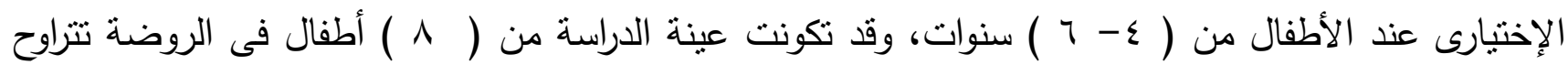
أعمارهم من ( ع - 7 ) سنوات بمتوسط أعمار 0 سنوات، طبق عليهم إختبار جودأنف هاريس للأكاء، قائمة ملاحظة إضطراب الصدت الإختيارى عند الأطفال من إعداد الباحثة وبرنامج إرشاد باللعب لخفض حدة إناء إضطراب الصمت الإختبارى من إعداد الباحثة، وتوصلت الدراسة إلى النتائج التالية:

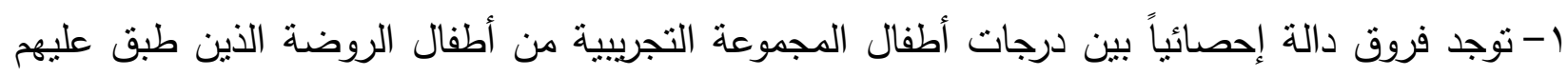

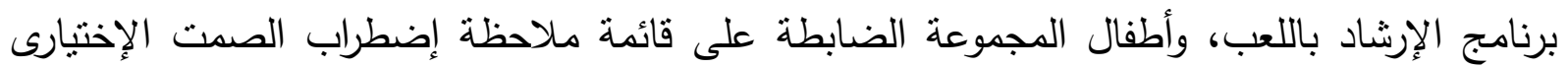
لصالح أطفال المجموعة التجريبية. 
The Effectiveness of Play Counseling Program for the reduction of the Selective Mutism to Children (4-6 years old)

\author{
Dr. Naglaa Mohammed Roby Sofy \\ Lecturer, in the Department of Kindergarten \\ Faculty of Education, Helwan University
}

\title{
Summary of the Study
}

The study was aimed at identifying the effectiveness of the counseling program to reduce the severity of selective silence disorder in children (4-6 years). The sample study consisted of (8) kindergarten children aged 4-6 years with an average age of 5 years, They were tested by Juden Harris for intelligence, a checklist of selective silence disorder in children prepared by the researcher and a counseling program to reduce the severity of selective silence disorder.The study discovered the following results:

1_There are statistically significant differences at $(0.05 \%)$ between the children of the experimental group of kindergarten who have been assigned the counseling program and the children of the control group in the list of selective silence disorder. 


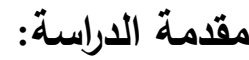

إضطراب الصمت الإختيارى هو إضطراب يتميز بضعف في التحدث في أوضاع محددة (متل المدرسة ،

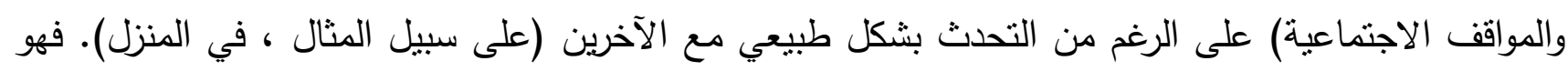

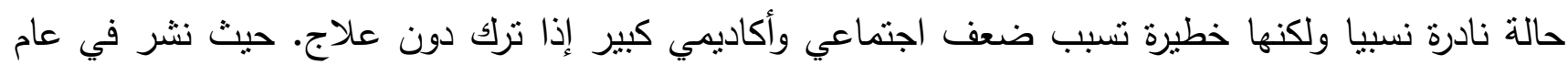

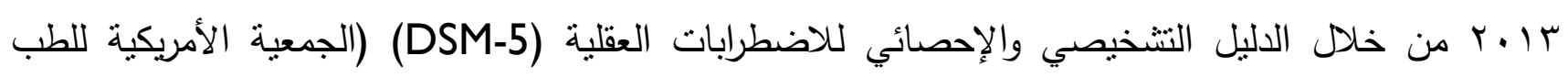

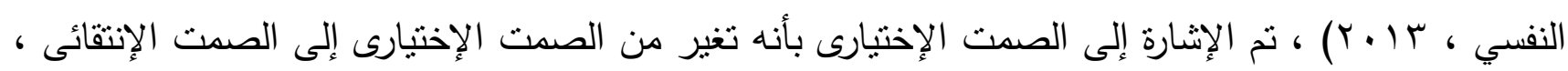
مما يعكس تحول في فهم الصمت الإختيارى من فعل الإرادة إلى عدم القدرة على الكلام في حالات محددة.

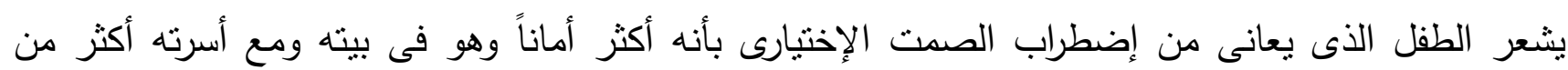

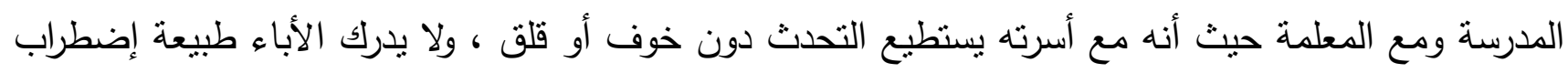

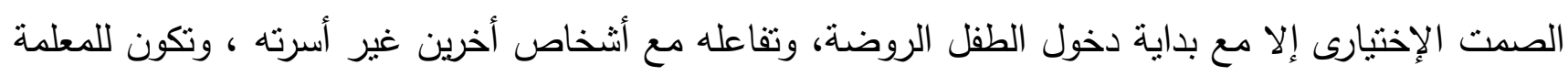
أو المعلم دور فى زيادة هذا الإضطراب.

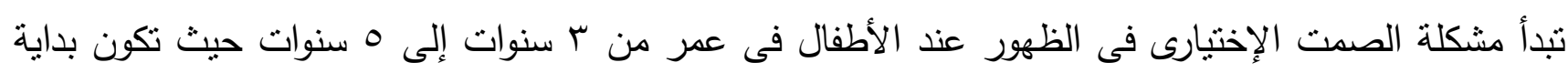

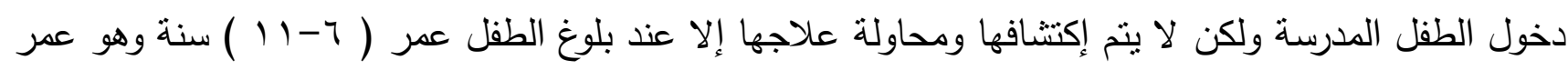
الطفل فى المرحلة الإبندائية، ويعد الإكتثاف المبكر لهذا الإضطراب ضرورة هامة حيث يساعد فى منع ظهور (Hung, Spencer\& Dronamraju, 2012, p.222)

المشكلات اللاحقة منل الشكلات الإجتماعية والمشكلات التعليمية.

وقد شخص إضطراب الصمت الإختيارى فى الدليل التشخيصى والإحصائى للإضطرابات النفسية الذى تصدره

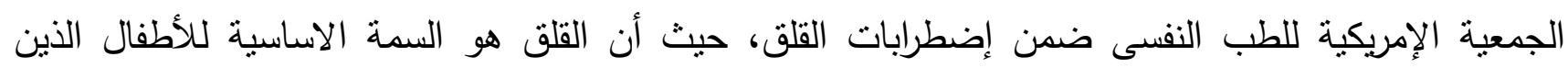

يعانون من هذا الإضطراب. (Muris \&Ollendick, 2015, p.151) وحيث أن اللعب يشكل أهمية كبيرة فى حياة الطفل، حيث يعتبر مظهراً من مظاهر السلوك الإنسانى فى مرحلة الطفولة المبكرة والتى تعد مرحلة وضع اللبنات الأولى فى تكوين شخصية الفرد، فهو يساعد الطفل على النمو

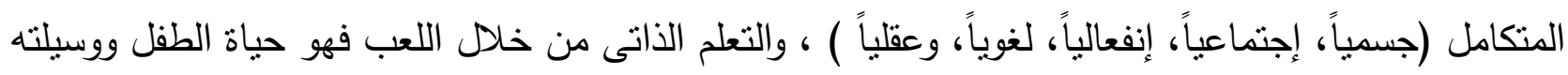
للنمو والتعلم السليم. وللعب أهمية نفسية فى حباة الطفل حيث يساعد الطفل فى التخلص من التوتر الإنفعالى والقلق الذى ينشأ من

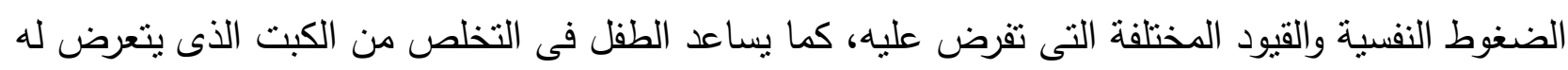

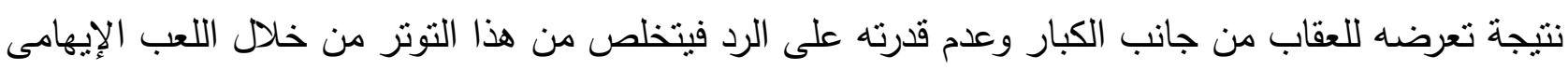

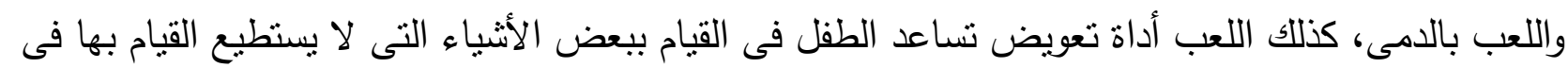
الواقع ، كما أنه وسيلة للتعبير عما يدور فى نفس الطفل ، كذلك يسهم فى تشخيص مشكلات الأطفال النفسية، 
وهو أيضا وسيلة لضبط، توجيه، وتصحيح السلوك حيث يساعد الطفل على التعرف على مشكلاته ويسهم فى

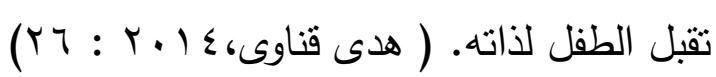
كما يعد الإرشاد باللعب أحد أهم مناهج العلاج النفسي للأطفال، باعتباره علاقة دينامية شخصية بين الطفل

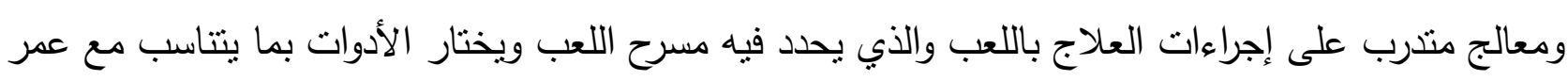
الطفل وخبرته وتتناسب مع مشكلة الطفل بما يسمح بتطوير علاقة آمنة للطفل يعبر فيها عن مشاعره وأفكاره وخبراته، وسلوكياته.

مشكلة الدراسة:

يثكل إضطراب الصمت الإختيارى عند الأطفال وبخاصة فى سن رياض الأطفال ( ع- 7 ) سنوات

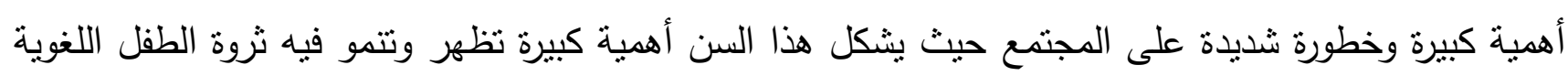

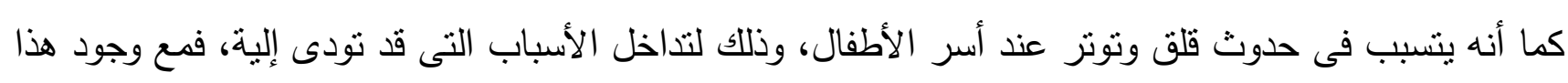
الإضطراب قد ينسبب فى بعض المشاكل اللغوية عند الطفل بالإضافة إلى المشاكل الإجتماعية التى يعانى منها

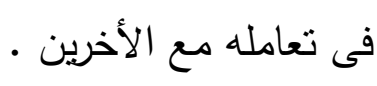
أن الأطفال الذين يعانون من الصمت الإختيارى لا يكونون صامتين "عن قصد". لكنهم غير قادرين على التفاعل في بعض المواقف بالكلام وعليه يكون عدم التحدث هو الطريقة التي يحمون بها أنفسهم من القلق الثنديد. والعقاب أو الضغط عليهم أو جعلهم يشعرون بالذنب. كما أن محاولة إجبار الطفل على الكلام يمكن أن تجعله لهانه

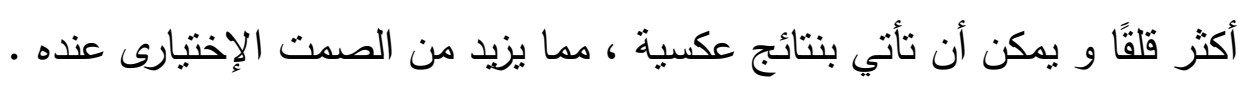

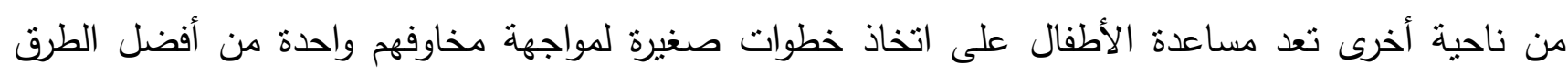

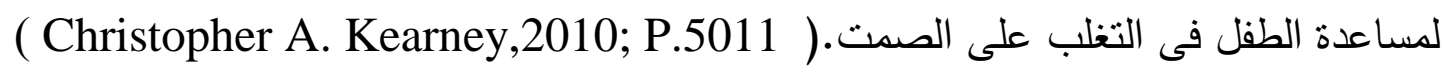
وقد أثنارت إليسا شيبون ( Elisa Shipon.20I3;pI أن أكثر من • 9\% من الأطفال الدصابين بالصمت

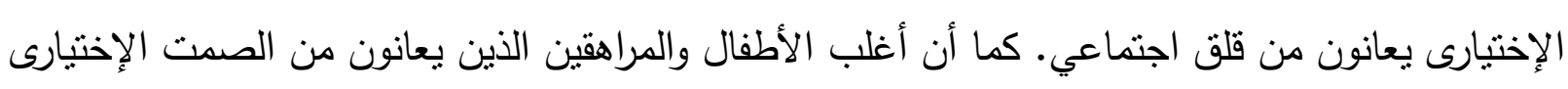
لايهر خوف حقيقي من التحدث والتفاعلات الاجتماعية.

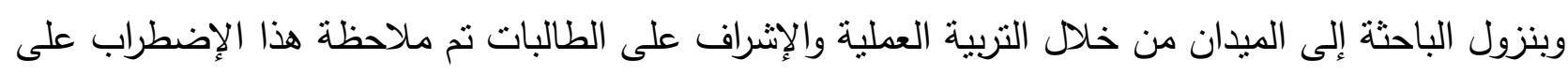

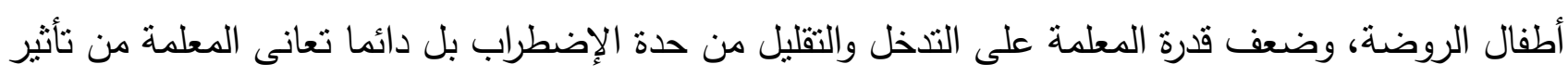

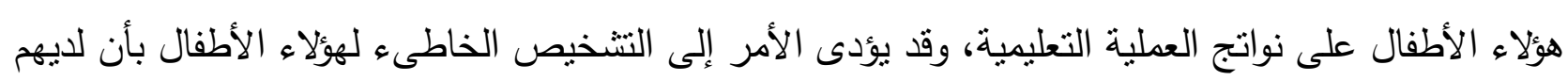

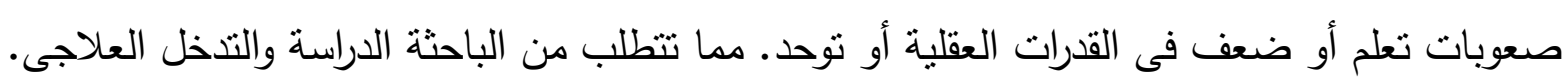
هذا، ويمكن صياغة مشكلة الدراسة الحالية في محاولة للإجابة على التساؤلات الآتية:

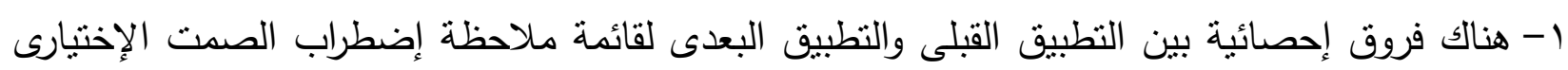

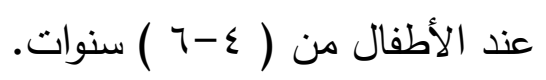


ץ- ما مدى فاعلية برنامج الإرشاد باللعب فى خفض إضطراب الصمت الإختيارى عند أطفال الروضة؟ أهداف الدراسة:

تهدف الدراسة الحالية إلى تحقيق الأهداف التالية: 1- الكثف عن مظاهر إضطراب الصمت الإختيارى عن أطفال الروضة. ץ- التحقق من وجود فروق بين متوسطات درجات التطبيق القبلى والبعدى لقائمة ملاحظة إضطراب الصمت الإختيارى لأطفال الروضة. ب- التحقق من مدى فاعلية برنامج الإرشاد باللعب فى خفض إضطراب الصمت الإختيارى عند أطفال الروضة.

أهمية الدراسةة: ترجع أهمية الدراسة الحالية لتتاولها لأحد الموضوعات البحثية المهمة وهو إضطراب الصمت الإختيارى عند أطفال الروضة، والتعرف على دور برامج الإرشاد باللعب فى خفض حدة هذا الإضطراب عند الأطفال، مما يسهم من الناحية النظرية في إثراء البحوث والدراسات في هذا الجانب، وإلقاء الضوء على هذا الموضوع الذي يشغل اهتمام شريحة عريضة من الأسر والمعلمين. أما من الناحية التطبيقية فتتضح أهمية الدراسة الحالية من خلال ما قد تسفر عنه من نتائج يمكن أن يستفاد منها التربوين من معلمات رياض الأطفال فى التعامل مع الأطفال وتعديل سلوكهم بما بحقق الرؤية التربوية للمجتمع. مصطات الاراسة:

أولاً: الصمث الإختيارى: Selective Mutism يعرفه ديفيدسون (Davidson, 2012, p. 11) بأنه حالة مرضية من حالات الاضطراب العاطفي والانفعالي وتتخص على أنها رفض كامل للكلام خارج المنزل، أو مع أشخاص غرباء فيكون صمتهم من اختيا رهم وليس نتيجة عيب خلقي، أو عضوى.

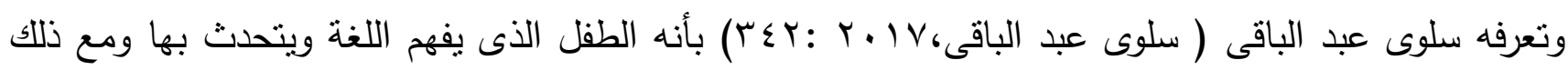
يرفض الحديث لسبب ما. وتعرف الباحثة في الدراسة الحالية الصمت الإختيارى بأنه عدم قدرة الطفل على الحديث فى مواقف إجتماعية محدة وغير ناتج عن نقص معرفى باللغة، أو خلل وظيفى فى أعضاء النطق والكلام. 
Play : ثَانياً: اللعب

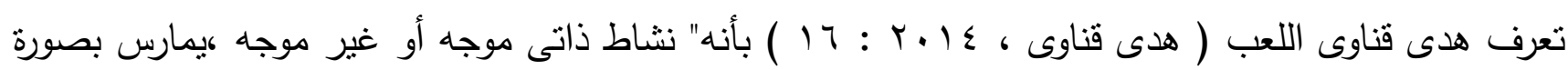

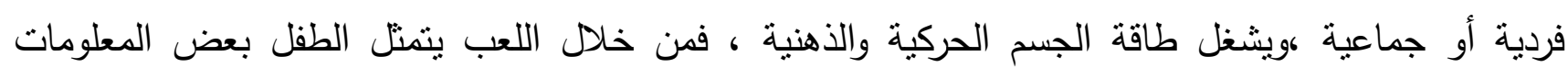
والمعارف والمهارات لتصبح جزءا من كيانه فتجلب له السرور والإستمناع فيتعلم وينمو ".

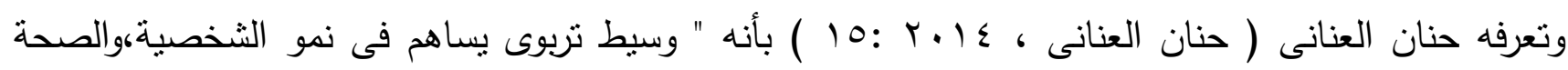

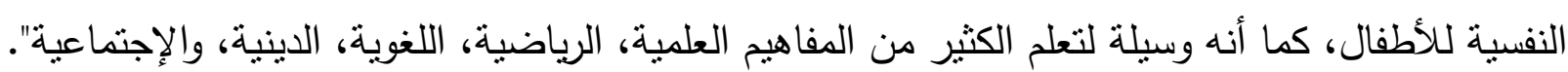

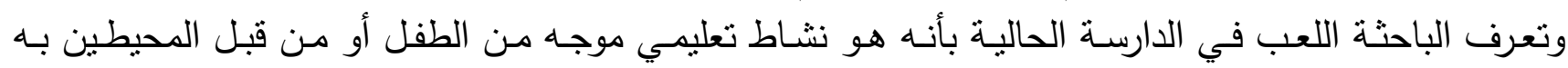
ويشارك فيه الطفل بما لديه من خبرات وقدرات وإمكانيات مما يساعد علي إنماء جوانب شخصيته بنديه بشكل متكامل.

أولاً: الإطار النظري للإراسة:

\section{Selective Mutism : الصمت الإختيّارى}

الصمت الإختيارى هو فنل الطفل فى التحدث فى بعض المواقف الإجتماعية وليس جمبعها، فقد يتحدث

فى مواقف معينة عندما يكون فى البيت أو مع الوالدين، ألا أنه يفشل فى التحدث فى المدرسة أو الأماكن الخارجية ويتفق مع هذة الحالة الخجل الثديد والإنسحاب والإعتماد على الوالدين. ( فريد مصطفى لئى

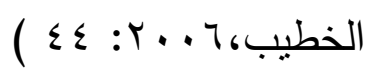

لا يتم اكتثاف هذا الاضطراب غالبًا إلى أن يبدأ الطفل في الذهاب إلى المدرسة وهنا تلاحظ المعلمه أن هناك

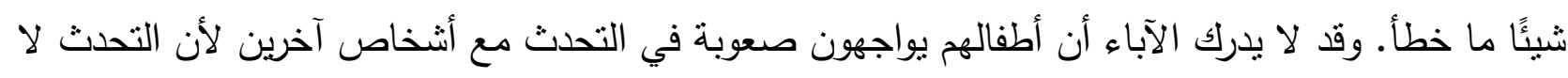

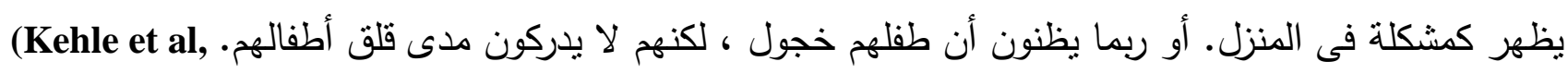
2012, p.95)

قد يكون الأطفال الذين لايهم صمت إختبارى قادرين فقط على التحدث بطريقة الهمس للمعلمين أو الأقران. أما البعض الآخر لا يكون قادرًا على هذة الطريقة ، وقد بيستمر الأطفال عام كامل دون تحدث.

عدم القدرة على الإجابة على الأسئلة الموجها لهم في الفصل ، حتى عندما يعرفون الإجابة الصحيحة ، وقد

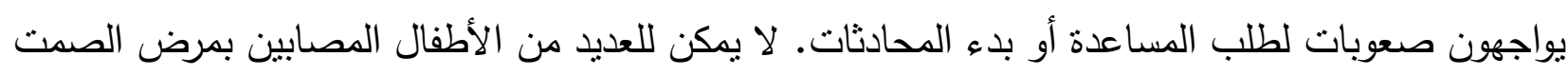

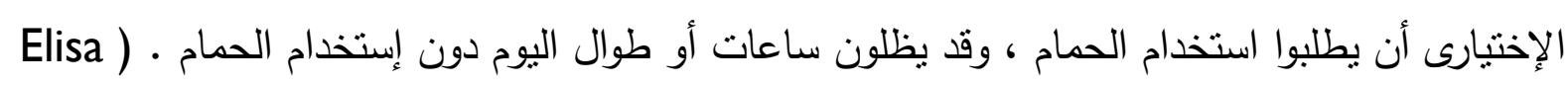




\section{أعراض الصمت الإختيارى عند الأطفالٍ:}

هناك خلط بين أعراض إضطراب الصمت الإختيارى وإضطرابات اللغة والتوحد ويجب علينا التقريق بينهم حيث أن أهم ما يميز إضطراب الصمت الإختيارى هو أن الطفل يتكلم بحرية فى مواقف محددة وفى مواقف أخرى يفق هذة القدة على الكلام والتحدث نتيجة القلق وعليه فيجب التشخيص الدقيق لهذا الإضطراب وذلك من خلال التقييم النفسى التعليمى الكامل.(Kotrba, 2015, p.27) وقد أشار كلا من ألى وأخرون وكيارنى( Kearney, 2010, p. 11) (Ale et al ,2013,p.278 ) وكذلك كيهلى وأخرون (Kehle et al, 2012, p.93) إلى أعراض إضطراب الصمت الإختيارى بالأتى: 1- تجنب المواقف الإجتماعية التى تنطلب مبادأة الحديث مع الأخرين. r- تجنب الإجابة على من بالباب أو التليفون أو أسئلة المدرسين. r- تجنب مواقف التقييم وخاصة التى تتطلب أداء لفظى. عـ الإختباء والصراخ والهروب ونوبات الغضب أذا طلب منهم الحديث بوجه عام. هـ ـ سرعة التنفس، وسرعة ضربات القلب. דـ الإهتزاز، الدوران، الإرتعاش، والثعور بالغثيان.

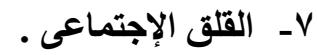

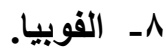

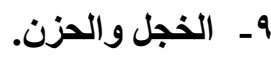

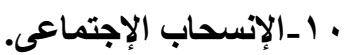
11 - الهمس أثناء الحديث. ب ا برف المدرسة.

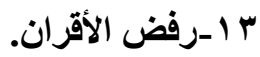
ـ ا ـ عدم إكمال المهام الأكاديمية اللفظية.

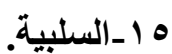
1 ـ التحديق فى الفضاء وقلة الإتصال البصرى. V ا غياب التعبيرات الوجهية، ونقص الإبتسام. 1 1 ـضعف لغة الجسد، وصعوبة فى الإستجابة غير اللفظية. 9 ا ـقد يحدث تبول نهارى لاأرادى، قيء متعمد ، وتردد فى المشى. • ب ـ أقل ثقة فى الذات أثناء التفاعل مع الأقران. 
أسباب الصمت الإختيارى:

أنثار كلا من ستين هاوسن وأخرون، و ديفيدسون (Steinhausen et al., 2006; Davidson, 2012) إلى الطى أحد أسباب الصدت الإختبارى وهو عامل الوراثة حيث أنه قد يكون أحد الوالدين، أو كلاهما قد بعانى من القلق الاجتماعي، والانظوائية، والرهاب الاجتماعي، ونوبات الخوف في مرحلة الطفولة.

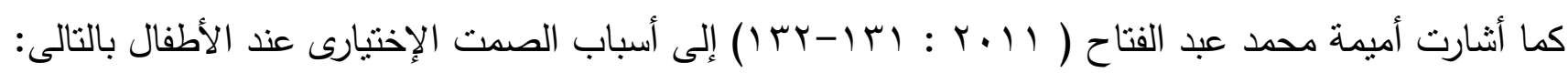
1- الإضطراب النفسى الذى يعانى منه الطفل نتيجة لصراعاته الاخلية. ץ- احساس الطفل المتزايد بالقلق الثديد حول عجزه المحتمل عن التعبير الصحيح كالحضانة أو الدرسة. r- الخوف من المدرسة ومن الخبرات الجديدة التى يعيشها الطفل فى المدرسة.

$$
\text { ـ - التعرض لصدمات نفسية أو خلافات زوجية. }
$$

7- تغيير مكان السكن أو تغيير الروضة أو المدرسة وبعد الطفل عن أصدقائه ومعلميه.

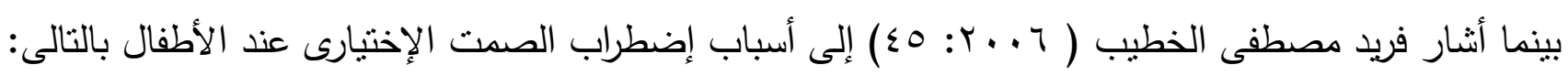
1- سيطرة الأم أو الحماية الزائدة للطفل أو الإنفصال عنه. r- عدم شعور الطفل بالأمان والقدرة على التواصل بسبب الخلافات الأسرية التى تحدث ألمام الطفل. r- سيطرة المعلم وكثرة الإنتقادات.

ع - الأزمات والصراعات النفسية سواء كانت منراكمة أو مفاجئة. ه- إضطرابات الكلام وما ينشأ عنها من سخرية الأخرين وأنتقادتهم. 7- حالات الخجل الثثديد والقلق المزمن والتوتز التى تقترن ببعض المواقف، والخبرات السيئة عند الطفل. طرق التخخل العلاجى لإضطراب الصمت الإختيارى:

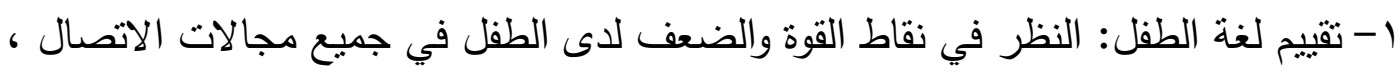

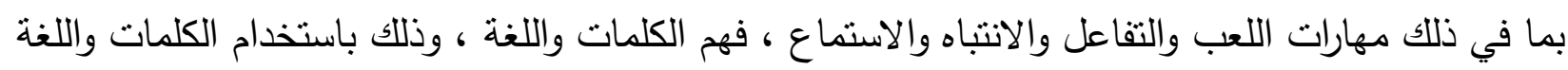
والتفاعلات الاجتماعية.

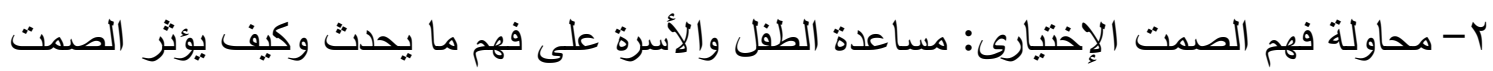
الإختبارى على الطفل عاطفيا.

r- التخفيف من القلق: العمل مع الطفل لتقليل القلق والإجهاد الذي قد يصاحب الصمت الإختبارى .

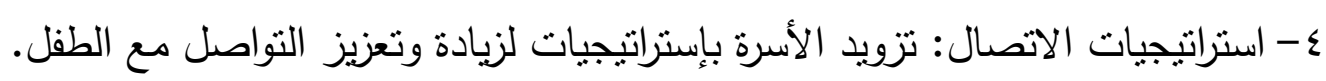

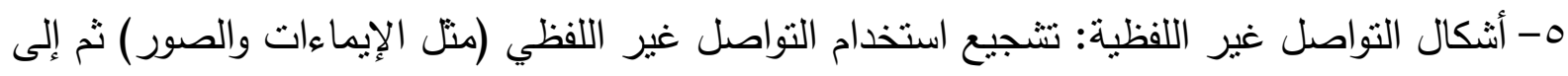
التواصل والتحرك تدريجيا نحو الطفل باستخدام الكلام ثم إلى التواصل داخل الفصل و / أو المنزل. 
צ- محاولات التواصل: تعزيز محاولات الاتصال بشكل إيجابي عند حدوثها (متل الهمس والإيماءات). V- حنع القرار : قدم خيارات للطفل وشجع الطفل على استخدامها.

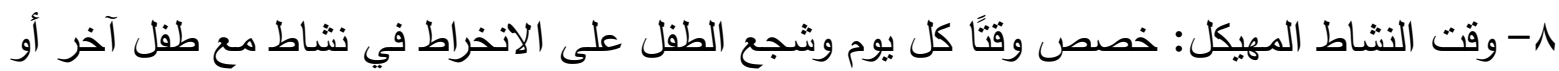

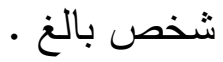

9-وقت المجموعة: قم بإعداد مجموعات صغيرة قد يشعر الطفل فيها أكثر بالرغبة فى التحدث المريح (على

$$
\text { سبيل المثال في المدرسة). }
$$

• 1 - متطوير النقة: بناء تقة الطفل من خلال إنثاء موقف يتحدث فيه الطفل بحرية ثم يغير الموقف

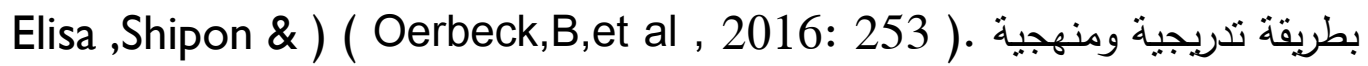

( Christy,Ann,2015:80-84

Play : اللعب

اللعب هو عبارة عن كل نثاط يقوم به الأطفال سواء كان موجه أو غير موجه من أجل تحقيق المتعه والنسلية ويستغله الكبار ليسهم فى تتمية شخصياتهم وسلوكياتهم بأبعادها المعرفية، الجسمية، الإجتماعية، والإنفعالية.

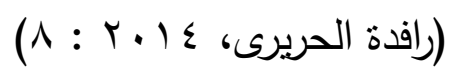

أهمية اللعب للطقل:

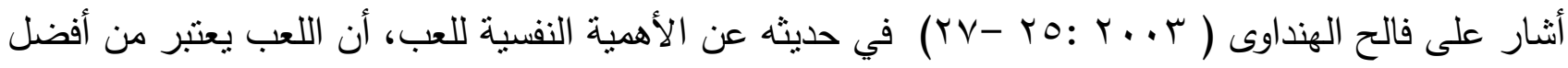
الوسائل للتخلص من الكبت، فالطفل الذي يعجز عن الرد على إهانة للكبار يلجا إلى كبت مشاعره ويشعر بالتوتر

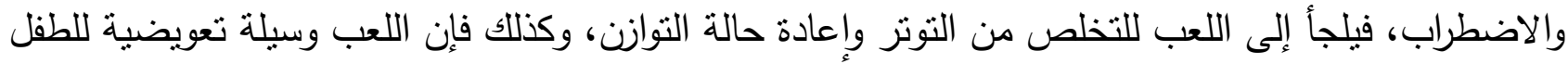

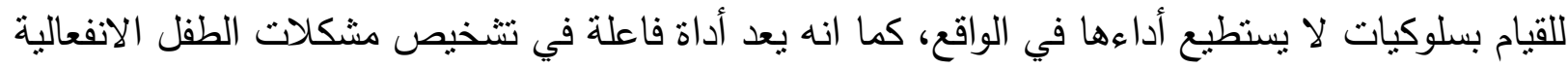

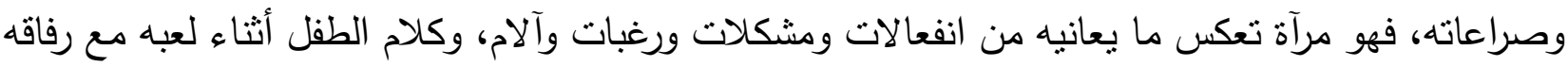
بصورة رمزية يعبر عن الجو الانفعالي الذي يعيشه في الأسرة وعلاقاته مع الآخرين.

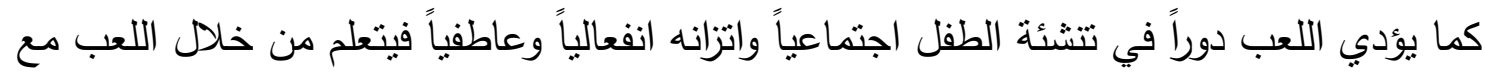

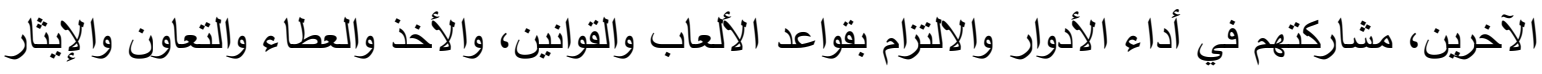

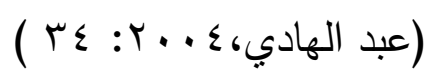

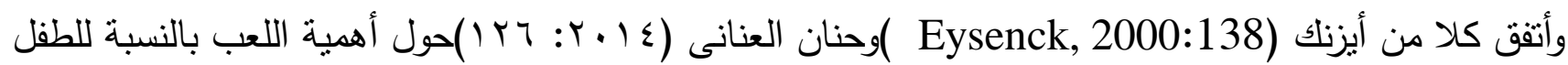
فى التالى:

1- يساعد الطفل في السيطرة على القلق والمخاوف والصراعات النفسية البسيطة.

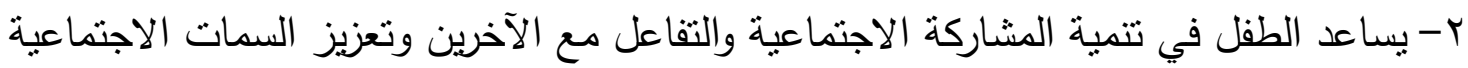

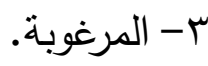
ع- يساعد في تتمية المهارات الحركية والنمو الجسمي. 
0- يساعد في تتمية مدركات الطفل وتتمية تفكيره. 7- يساعد في التعرف على نفسه وكثف إمكاناته. V- يساعد الطفل في عمليات التعلم. 1- يساعد اللعب فى تشخيص المشكلات التى يعانى منها الطفل. 9- يساعد فى تتمية مشاعرهم ، وتفريغ طاقاتهم الإنفعالية. كما أن الأرشاد باللعب له فوائد هامة بالنسبة للطقل وهى متمثلة فى التالى: ا - يعد مجالا سمحاً للتعبير عن المشاعر والرغبات والصراعات وتحويل المشلعر السلبية كالغضب والعدوان إلى مشاعر بديلة، والتعبير عنها تعبيراً رمزياً. r- يساعد الطفل على الإستبصار بمشاكلة ومعرفة أسبابها. r- ينمى الميول والثقة بالنفس ، كما ينمى الخيال. ؟- يعطى الفرصة للطفل لإختبار الواقع. 0- وسيلة لتحقيق التسامى والإعلاء لبعض الدوافع كالعدوان والغضب. 7- يستخدم فى مجال التشخيص والكثف عن مشاكل الأطفال.

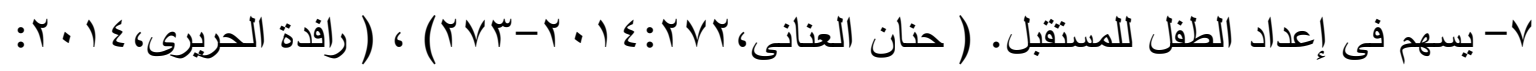
$(r) \leqslant-r) r$ وقد أكد دراسة كريستين ومينى ( Kristin, K. Meany- Walen, 2010 ) على أهمية اللعب فى تعديل سلوك الأطفال،حيث هدفت الدراسة إلى إختبار فعالية العلاج باللعب لخفض السلوكيات الفوضوية لدى أطفال بمرحلة رياض الأطفال، وأسفرت نتائج الدراسة عن فاعلية البرنامج فى تحسين سلوك الأطفال. كما أكدت دراسة منى كمال أمين( ع ا ـ r ) والتى هدفت إلى التحقق من مدى فعالية العلاج باللعب في الحد من بعض مشكلات الانضباط السلوكي، وأسفرت نتائج الدراسة إلى عن فاعلية برنامج العلاج باللعب فى تعديل سلوك

الأطفال

ثثانياً: الاراسات والبحوث السابقة:

تعرض الباحثة فيما يلي عدداً من الدراسات والبحوث المرتبطة بموضوع الدراسة الحالية: استهدفت دراسة كاربون ( Carbone et al., 2010 ) الكثف عن العلاقة بين الصمت الاختياري والمهارات الاجتماعية والسلوكية والعاطفية لدى الأطفال، و طبقت الدراسة على عينة قوامها ( 101 ) طفلا يعانون من

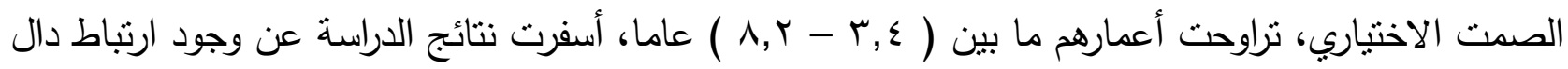
بين الصمت الاختياري وضعف المهارات الاجتماعية والسلوكية والعاطفية. بينما استهدفت دراسة لانج ( Lang et al., 2011 ) الكثف عن فعالية التذخل السلوكي في علاج 


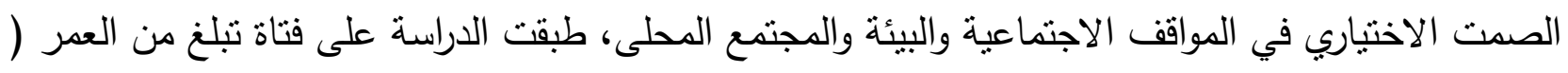

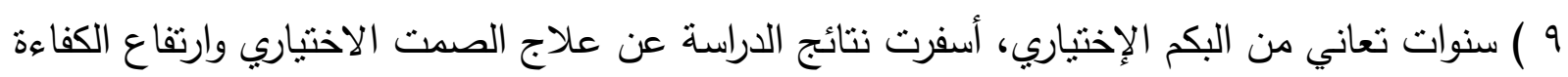

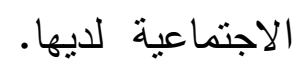

كما استهدفت دراسة هارود ( Harwood and Bork, 2011 ) الكثف عن فعالية برنامج تدريبي قائم على الكائ التواصل اللغوي في ورش التدريب المهني لدى الأطفال ذوي الصمت الاختباري، طبقت الدراسة على عينة قوامها

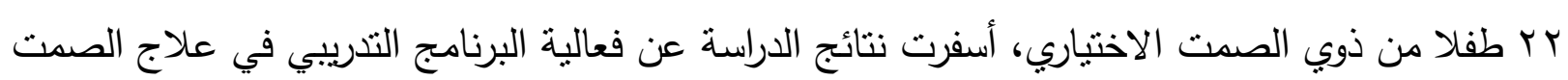
الاختباري وزيادة التواصل اللغوي لدى الأطفال. فيما استهدفت دراسة يونج ( Young et al., 2012 ) الكثف عن العلاقة بين الصمت الاختياري والكفاءة

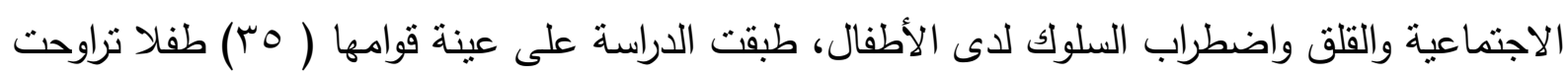

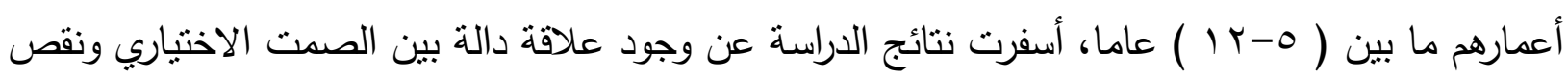
الكفاءة الاجتماعية وشدة القلق واضطراب السلوك. بينما استهدفت دراسة أوربك ( Oerbeck et al., 2012 ) الكثف عن فعالية برنامج متعدد الوسائط لعلاج

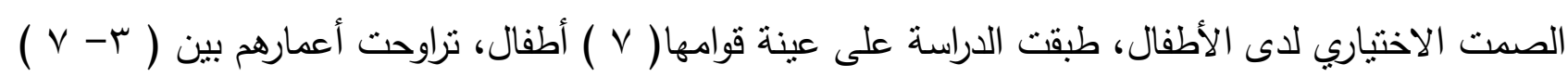

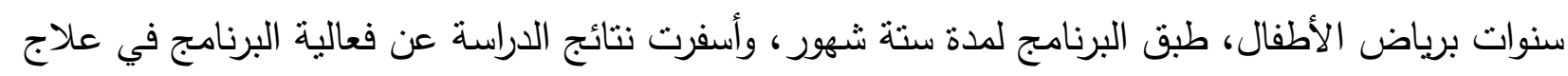
الصمت الاختياري لدى الأطفال.

أما دراسة باسيفيرتا ( Paasivirta, 2012 ) فقد استهدفت الكثف عن فعالية البرامج التدريبية في علاج

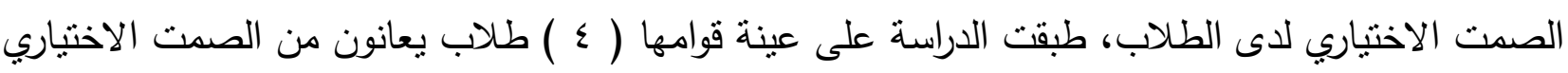
تراوحت أعمارهم ما بين ( V-0 ) سنوات ، وتم تطبيق البرنامج على مجموعة من المعلمين لاكتساب تقنيات

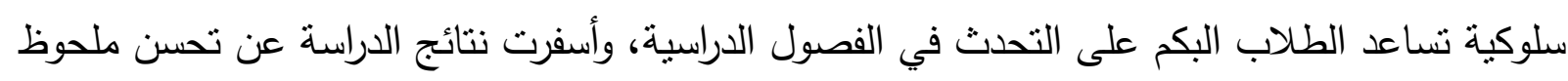
وخفض الصمت الاختياري لاى هؤلاء الأطفال.

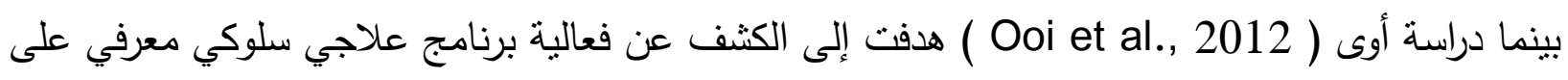

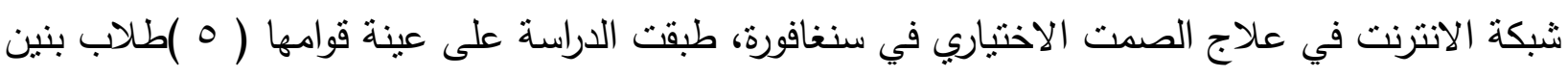

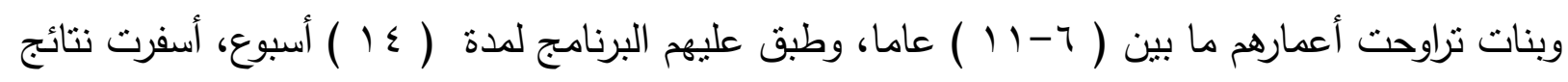

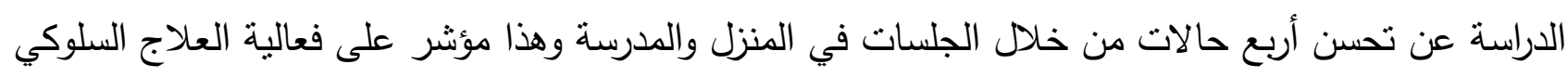
المعرفي في علاج الصمت الاختياري

ودراسة كلاين ( Klein et al., 2012 ) التى هدفت إلى الكثف عن فعالية العلاج السلوكي من خلال

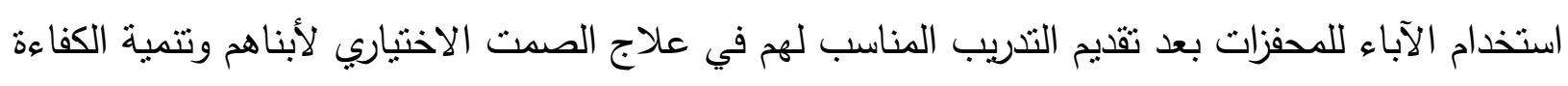

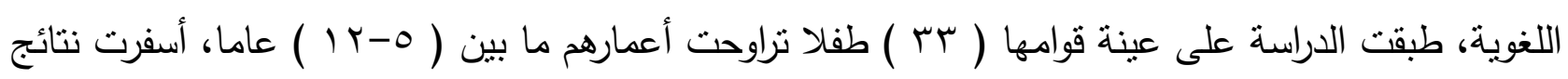
الدراسة عن فعالية استخدام المعززات في علاج الصمت الاختياري لدى هؤلاء الأطفال. 
كما هدفت دراسة مينتيل و كارنويل ( Mitchell and Kratochwill, 2013 ) إلى الكثف عن فعالية العلاج

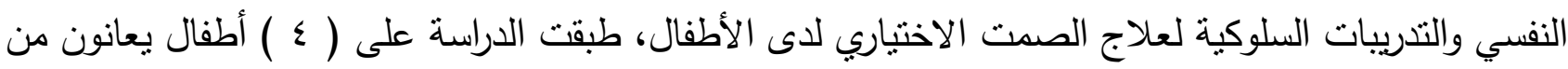
الصمت الاختياري، أسفرت نتائج الدراسة عن فعالية العلاج النفسي في خفض الصدت الاختياري لاى هؤلاء

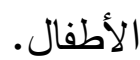

بينما أثنارت دراسة بيرجمان ( Bergman et a1, 2103 (الى الكثف عن فعالية العلاج السلوكي في علاج الصمت الاختياري لدى الطلاب، طبقت الدراسة على عينة قوامها ( إ طفلا ) يعانون من البكم الاختياري

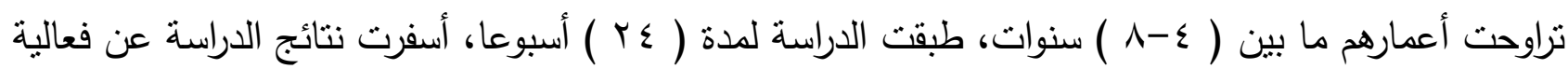
العلاج السلوكي في خفض الصمت الاختياري.

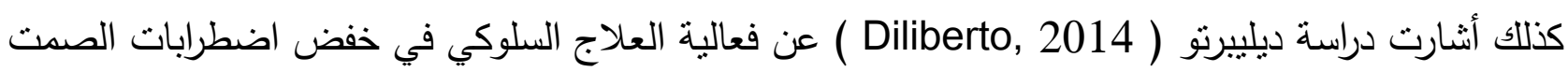

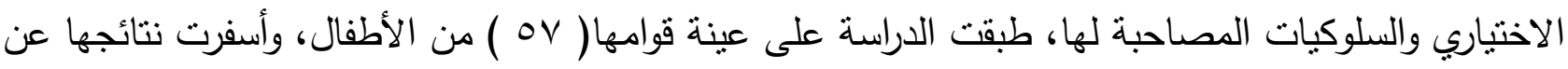

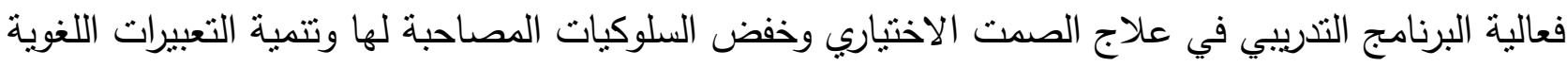

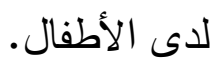

أما دراسة نيوبيرى ( Newberry, 2014 ) فقد استهدفت الكثف عن فعالية برنامج تدريبي باستخدام نمذجة

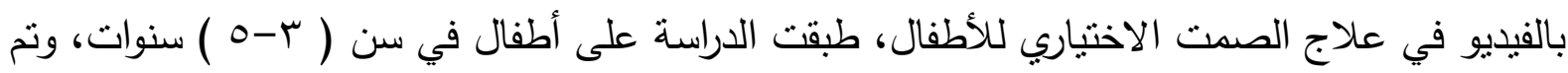

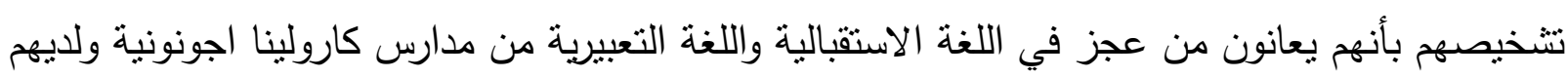

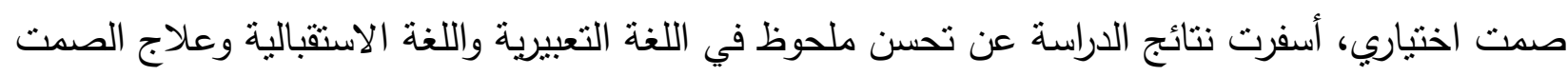

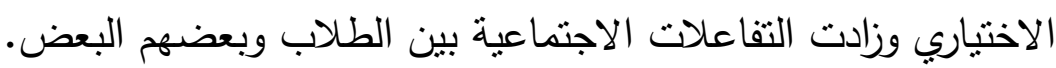

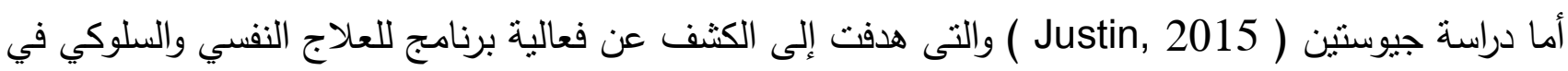

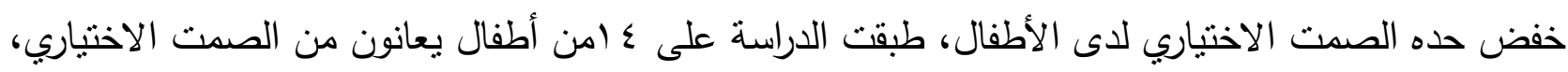
أسفرت نتائج الدراسة عن فعالية العلاج النفسي والسلوكي في خفض الصفت الصفت الاختباري لدى هؤلاء الأطفال وتحسن ملحوظ في خفض حده القلق الاجتماعي.

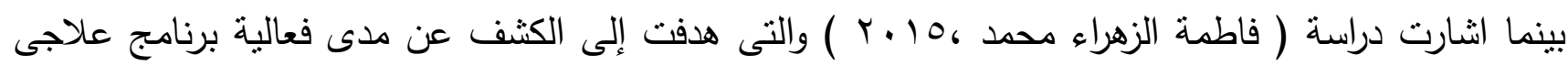

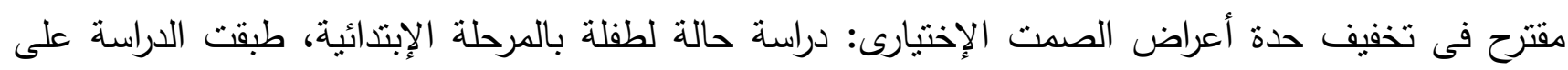

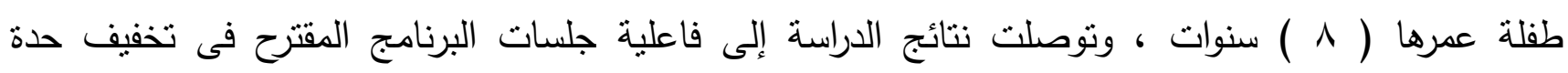
الأعراض المصاحبة لإضراب الصدت الإختيارى لاى الطفلة وقدرتها على التفاعل الإيجابى مع مجتمع الأقران.

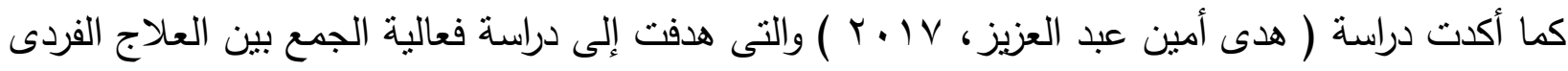

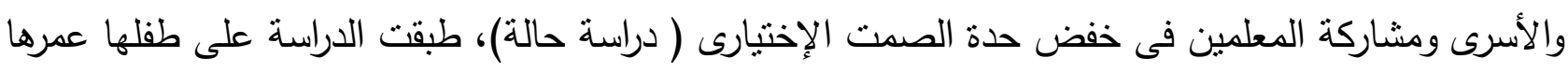


7 سنوات ، وأسفرت نتائج الدراسة عن فعالية كلا من العلاج الفردى والأسرى وكذلك مشاركة المعلمين فى خفض الطض حدة الصمت الإختيارى عند الطفلة.

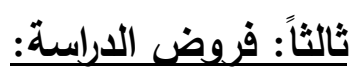
في ضوء الإطار النظري وما أسفرت عنه نتائج البحوث والدراسات السابقة أمكن للباحثة صياغة فروض

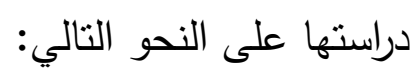
1-نوجد فروق دالة إحصائياً بين درجات أطفال المجموعة التجريبية من أطفال الروضة الذين طبق عليهم

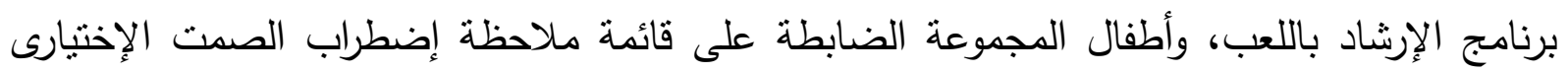
لصالح أطفال المجموعة التجريبية.

\section{منهج الاراسةة :}

ينتمي هذا البحث إلى فئة البحوث التي تستهدف دراسة العلاقات السببية بين المتغيرات واختبارها، ويعد المنهج

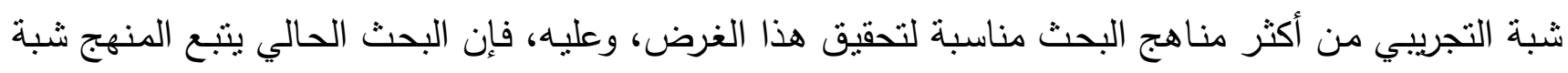
التجريبي. متغيرات البحث:

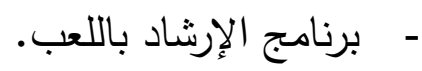

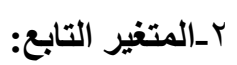
- اضطراب الصدت الإختيارى عند الأطفال. التصميم التجريبي للبحث:

ويوضحه الجدول النالي على ضوء نمط المتغير المستقل. جدول (1): التصميم التجريبي للبحث

\begin{tabular}{|c|c|c|}
\hline المتغيرات التابعة & المجموعة التجريبية & المجموعة الضابطة \\
\hline \multirow{2}{*}{ إضطراب الصمت الإختيارى } & برنامج الإرشاد باللعب & \multirow{2}{*}{ موقف تعلم عادى } \\
\hline & مجموعة تجريبية & \\
\hline
\end{tabular}


قامت الباحثة بتطبيق الدراسة الحالية على أطفال الروضة من ( ع-7 ) سنوات بروضة ( المشكاة

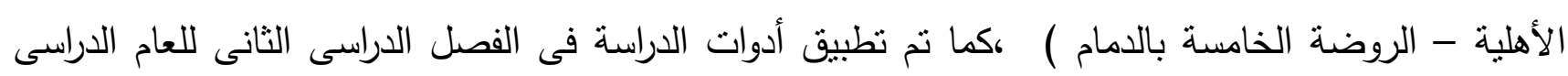
$\cdot r+1 \Lambda-r \cdot 1 V$ إجراعات الدراسةة: أولاً: عينة الاراسة: تكونت عينة الدراسة في صورتها النهائية من مجموعتين ( تجريبية وضابطة) قوامهما (^) أطفال من

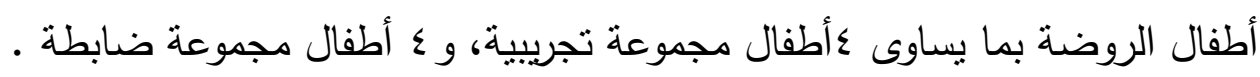

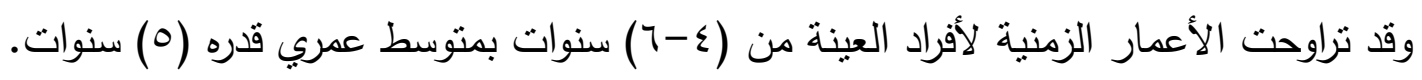

$$
\text { ثانباً: أدوات الدراسة: }
$$

أُعِدّ هذا الاختبار بهدف قياس مدى التجانس لدى طلاب الدجموعتين التجريبية والضابطة للبحث، قبل البدء

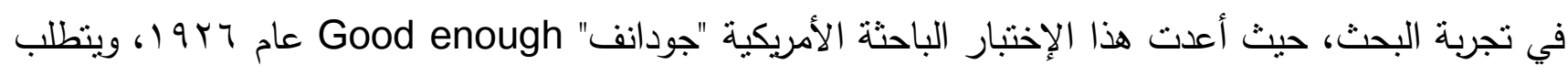

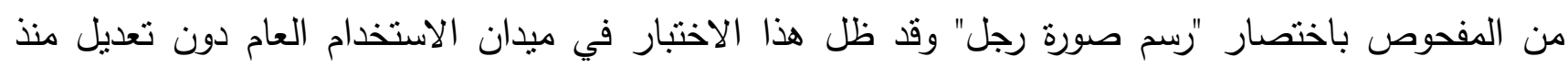

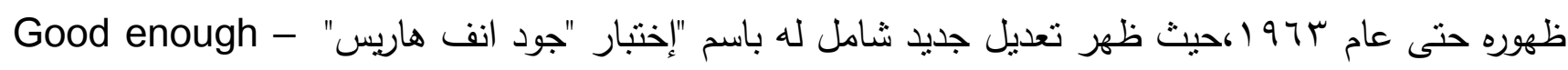

Harris Drawing test

ويؤكد هذا التعديل على دقة الطفل في الملاحظة وارتقاء تفكيره الهجرد، وليس المهارة الفنية في الرسم،

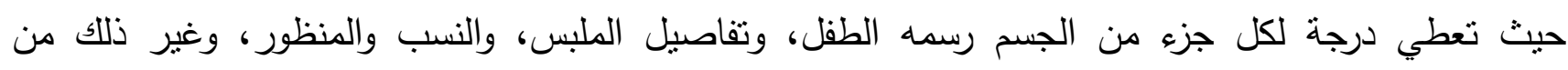

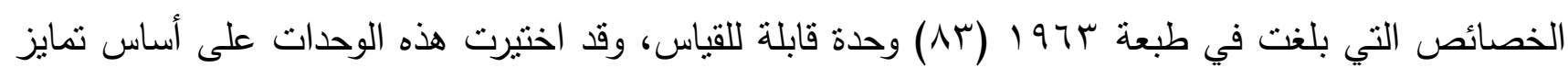

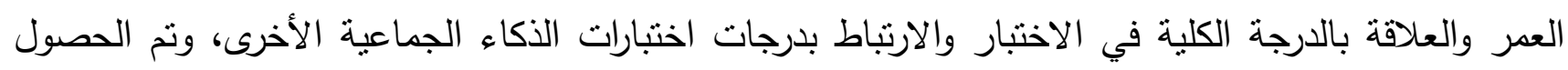

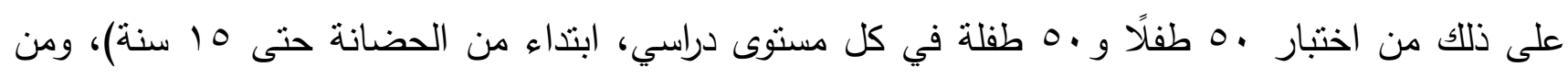

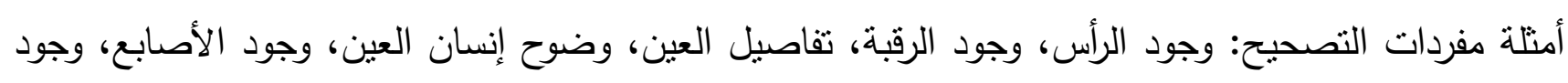
الساقين..الخ.

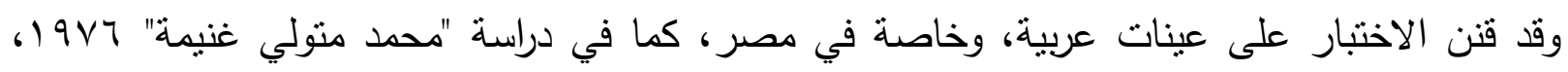

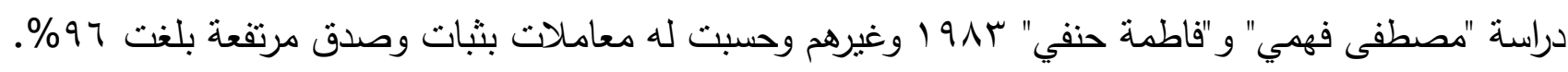
واستعانت الباحثة بهذا الإختبار للأسباب التالية: 1- أنه مناسب لعمر عينة البحث ع - 7 سنوات. r- سهولة تصحيحه. 


$$
\text { r- ال إحتاج إلى مهارات لغوية. }
$$

تم بدء تحليل نتائج اختبار رسم الرجل "لجودانف هاريس" للأكاء؛ وذلك بهدف التعرف على مدى تجانس

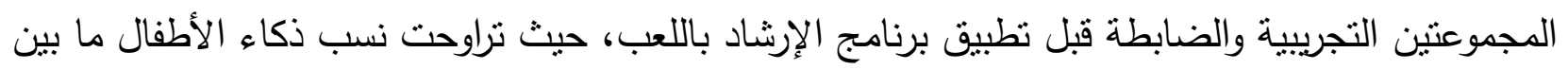

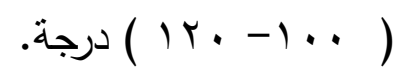

جدول (ץ): يوضح دلالة الفروق بين المجموعتين التجريبية والضابطة فى اختبار رسم الرجل للأكاء للتحقق

\begin{tabular}{|c|c|c|c|c|c|c|c|}
\hline الإحصائية & قيمة ( U U ) & قيمة ( U ) & متوسط & الإنحراف & الحستوسط & عداد & المجموعة \\
\hline \multirow[b]{2}{*}{ غير دالة } & r Y ع r & \multirow[b]{2}{*}{$\leqslant V, 0$} & $1,, v 0$ & $r, Y$ & 9. & $\varepsilon$ & تجريبية \\
\hline & مسنوى دلاله & & 10,70 & $Y, Y$ & $q Y, V D$ & $\varepsilon$ & ضابطة \\
\hline
\end{tabular}
من تجانس المجموعات بإستخدام إختبار مان ويتنى لجنين

يتضح من الجدول السابق عدم وجود فروق بين المجوعتين التجريبية والضابطة فى نسب الذكاء مما يؤكد تكافؤ

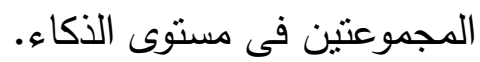

\section{r- قائمة ملاحظة إضطرب الصمت الإختبارى عند أطفال الروضة إعداد الباحثة.} وصف قائمة الملاحظة:

تتكون القائمة من (· r) بنداً تتاولت أهم سمات الأطفال الذين يعانون من إضطراب الصدت الإختبارى،

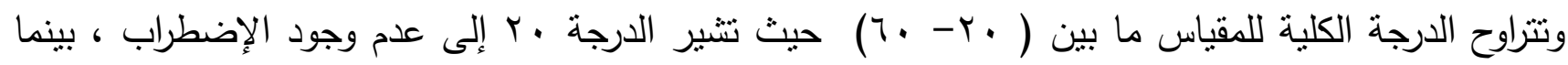

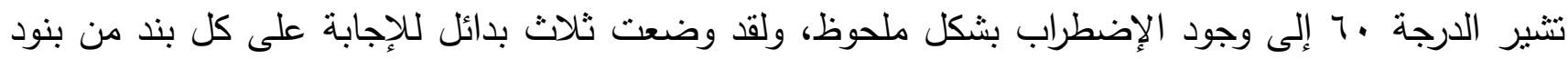

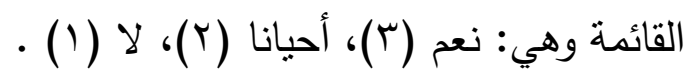

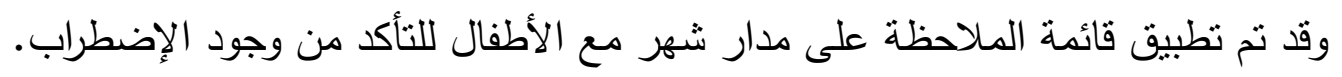

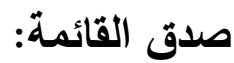
وقد قامت الباحثة بإجراء صدق قائمة الملاحظة من خلال حساب الاتساق الداخلي للقائمة وذلك من خلال حساب معامل الارتباط بين المفردة والدرجة الكلية للاختيار . 


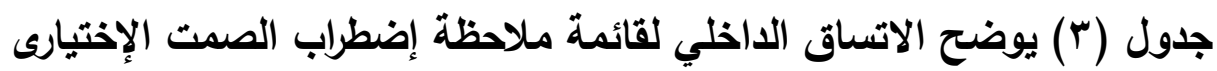

\begin{tabular}{|c|c|c|c|}
\hline الارجة الكلية للبعد & المفردة & الدرجة الكلية للبعد & المفردة \\
\hline$\cdot, r \wedge 0^{* *}$ & 11 & $\cdot, \varepsilon \leqslant . "$ & 1 \\
\hline$\cdot, \Sigma \cdot r^{* * *}$ & ir & $\cdot, \varepsilon) \varepsilon^{* * *}$ & $r$ \\
\hline$\cdot, \Gamma 99^{* *}$ & $\pi$ & $\cdot, 00 r^{* * *}$ & $\mu$ \\
\hline$\cdot, \varepsilon \cdot 0^{* *}$ & $1 \varepsilon$ & $\cdot, r 19^{* * *}$ & $\varepsilon$ \\
\hline$\cdot, \Gamma \nvdash \Lambda^{* *}$ & 10 & .,Yフ "** & 0 \\
\hline$\cdot, 00 \mathrm{~V}$ "* & 17 & 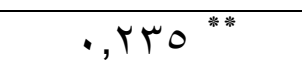 & 7 \\
\hline$\cdot, Y 1)^{* *}$ & IV & •, YVY ** & V \\
\hline$\cdot, I V V^{*}$ & 11 & $\cdot, \Sigma \Gamma \Lambda^{* * *}$ & $\wedge$ \\
\hline$\cdot, \varepsilon Y Y^{* *}$ & 19 & $\cdot, \Upsilon \wedge \wedge \wedge^{* *}$ & 9 \\
\hline$\cdot, \Gamma 19^{* * *}$ & $r$. & • & 1. \\
\hline
\end{tabular}

ملحوظة: * تعنى دالة عند مستوى 0 .,.

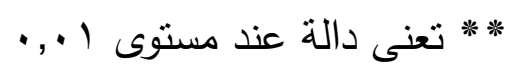

ثُبات قائمة ملاحظة إضطراب الصمت الإختبارى:

قامت الباحثة بحساب ثبات الاختبار بعدة طرق وهي بطريقة معامل الفاكرونباخ ومعامل التجزئة النصفية

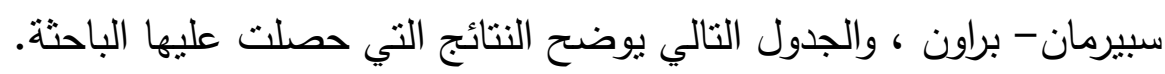

جدول (؛ ) يوضح حساب معامل الثبات لقائمة ملاحظة إضطراب الصمت الإختيارى بمعامل الفاكرونباخ معامل التجزئة النصفية سبيرمان -براون

\begin{tabular}{|c|c|c|c|}
\hline سبرمل التجزئة & معامل ألفا & عدد المفردات & القائمة \\
\hline$\cdot, v \cdot T$ & $\cdot, V \cdot r$ & $r$. & إضطراب الصمت \\
\hline
\end{tabular}


r-برنامـج الإرشاد باللعب لخفض حدة إضطراب الصمث الإختيارى: إعداد الباحثة

أهداف البرنامـج:

أ-الاهرف العام للبرنامجج:

يهرف البرنامج غلى خفض حدة إضطراب الصمت الإختيارى عند أطفال الروضة من ( ع-7 ) سنوات، بما يسهم فى مساعدة الأطفال على النمو بشكل صحيح ومتكامل. ب-الأهداف الإحرائية للبرنامج: - تتمية الثقة بالنفس وتدعيم الذات - تتمية مهارات الاتصال والتواصل بفعالية مع الآخرين - تتمية قدرة الطفل على التعبير الكلامي. - تدريب الطفل على التواصل البصري والحوار والمناقنتة - تتمية قدرة الطفل على الاندماج في العمل - تتمية قدرة الطفل على التعبير عن ذاته وعن مشاعره - تتمية قدرة الطفل على المشاركة في الأنشطة التى تقدمها المعلمة

\section{القتيات المستخدمة:}

1 - الحث و التلقين: بهذف حث الطفل على أداء سلوك محدد. r- تشكيل السلوك: هو تدعيم السلوك الذي يقترب تدريجيا من السلوك المرغوب، أو يقاربه من خطوات

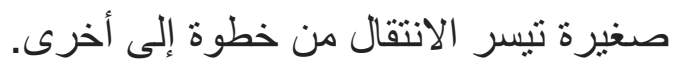

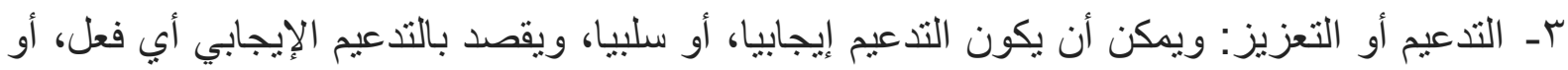

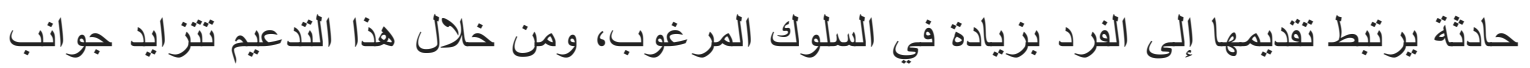

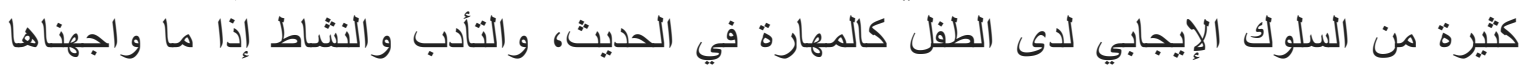
بالانتباه. ــ النمذجة و التقليد: جزء أساسي من بر امج كثيرة لتعديل السلوك. وهي تستند إلى افتر اض أن الإنسان

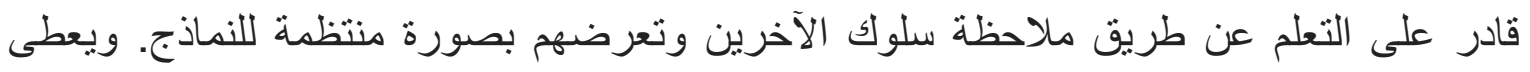

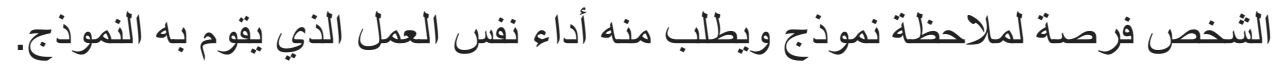

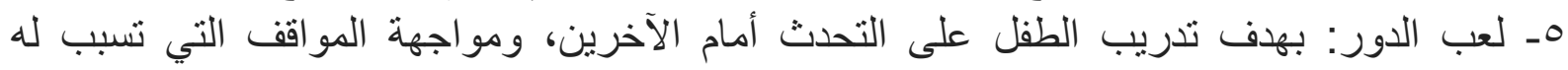

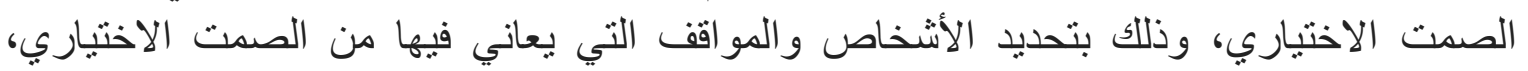


وقيامه بمساعدة زملائه بلعب دور المتحدث فيها، مع زيادة عدد من يتحدث إليهم تدريجيا، كمواقف طرح الأسئلة و الإجابة عليها.

\section{يرنامهج الإرشاد باللعب:}

أشتثل البرنامج على عدد ( ع r ) جلسة كما هو موضح بالجدول التالى: جدول ( 0 ) يوضح جلسات البرنامج ، المدة الزمنية، الفنيات المستخدمة ومحتوى الجلسات

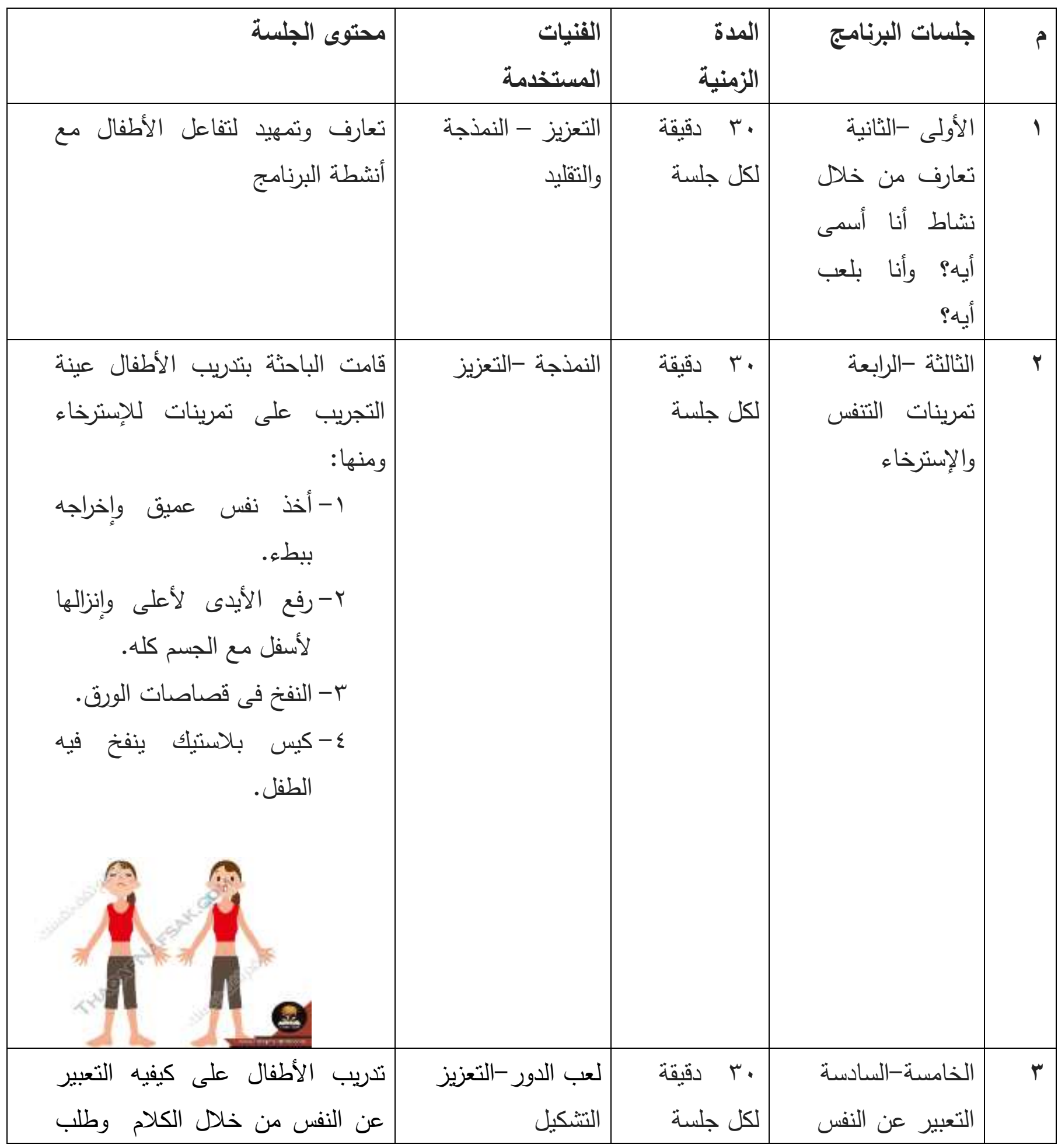




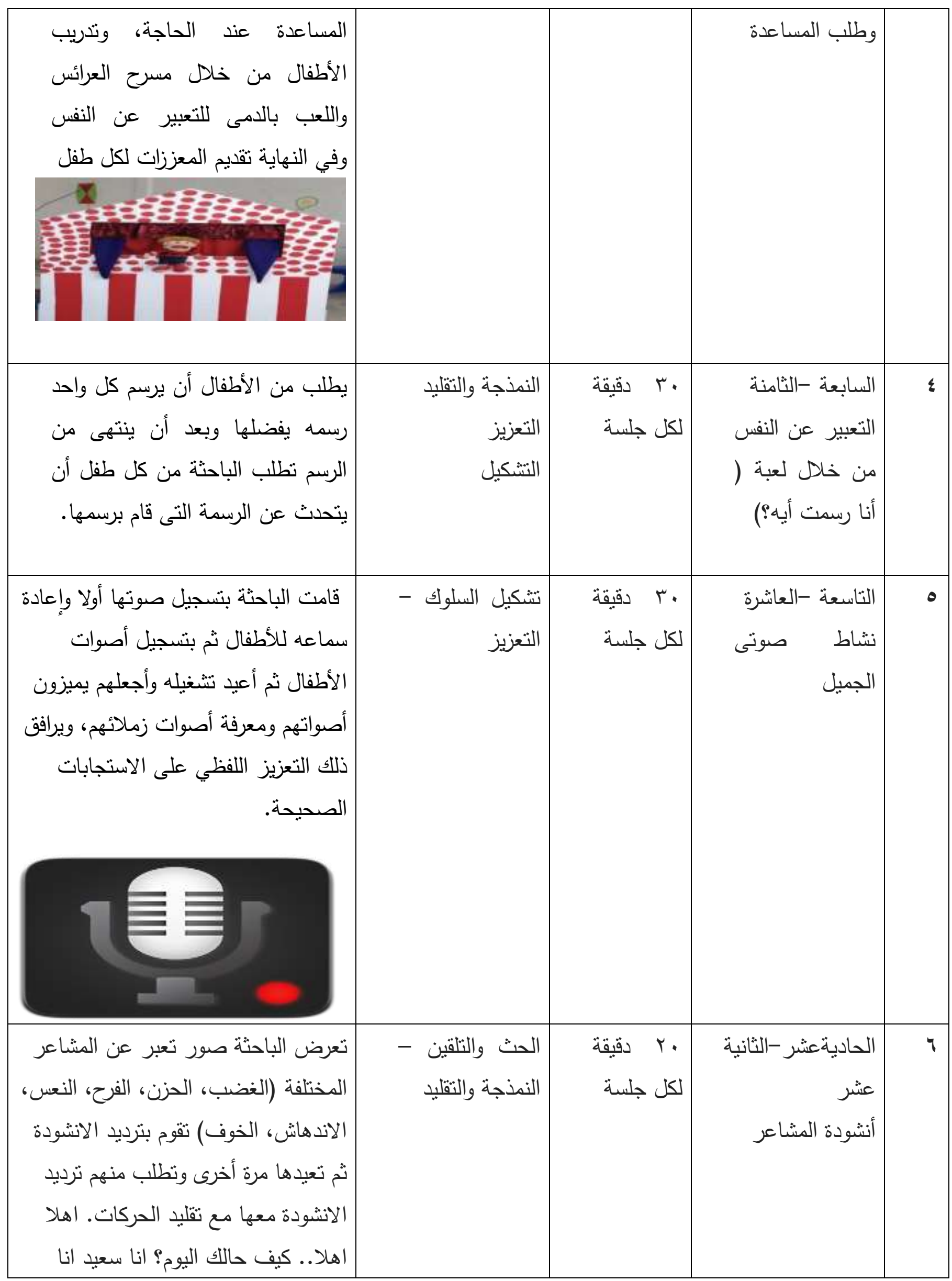




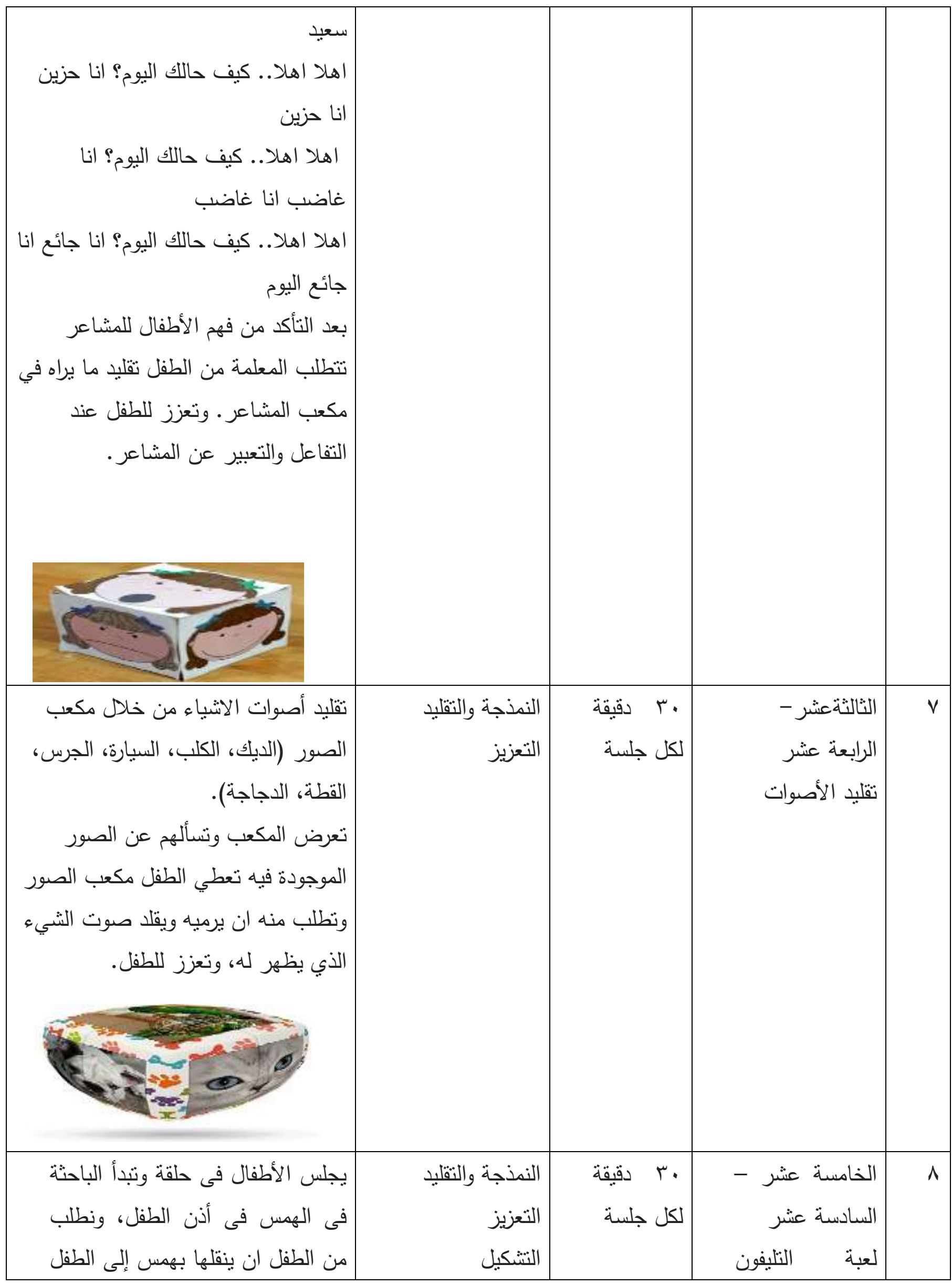




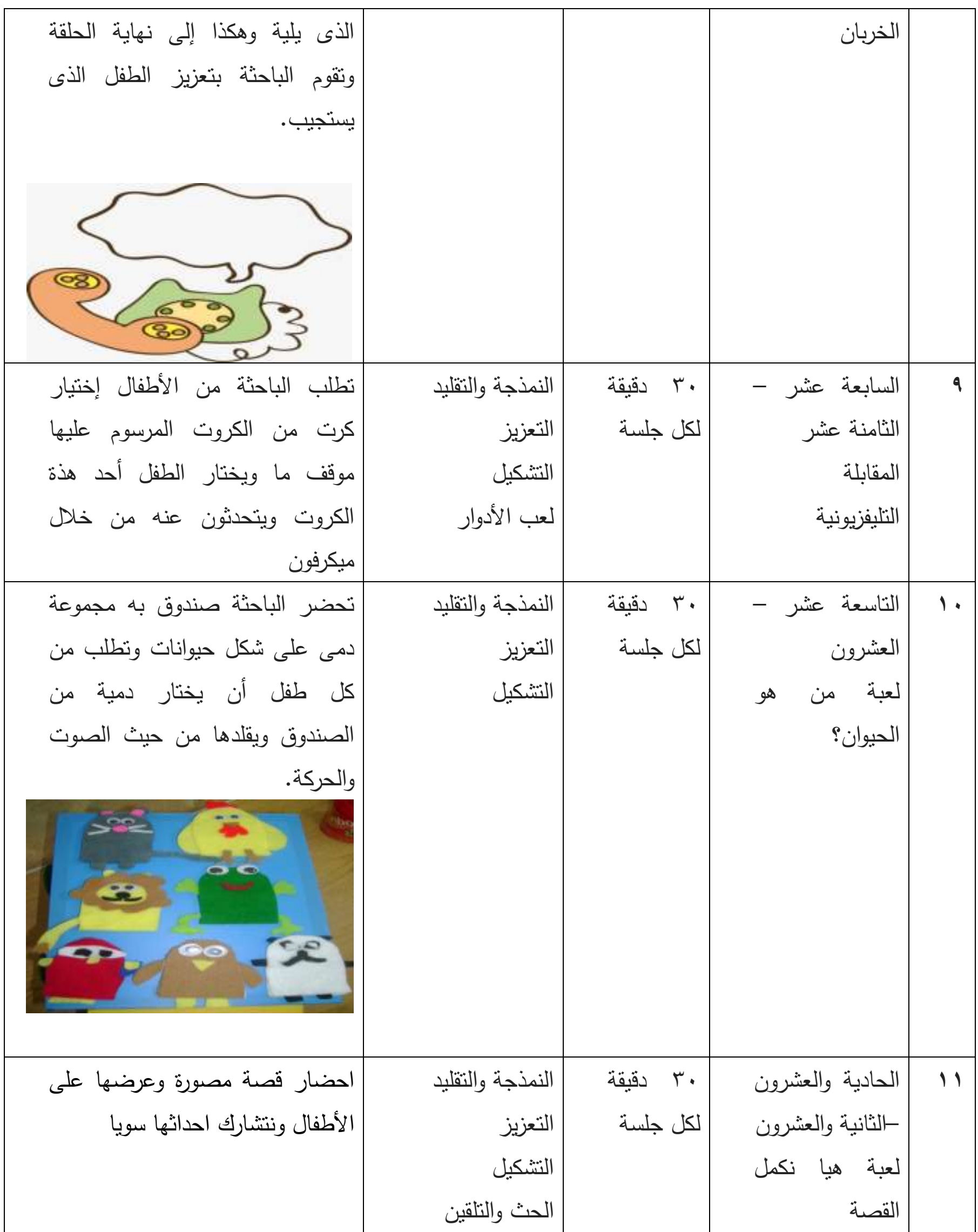




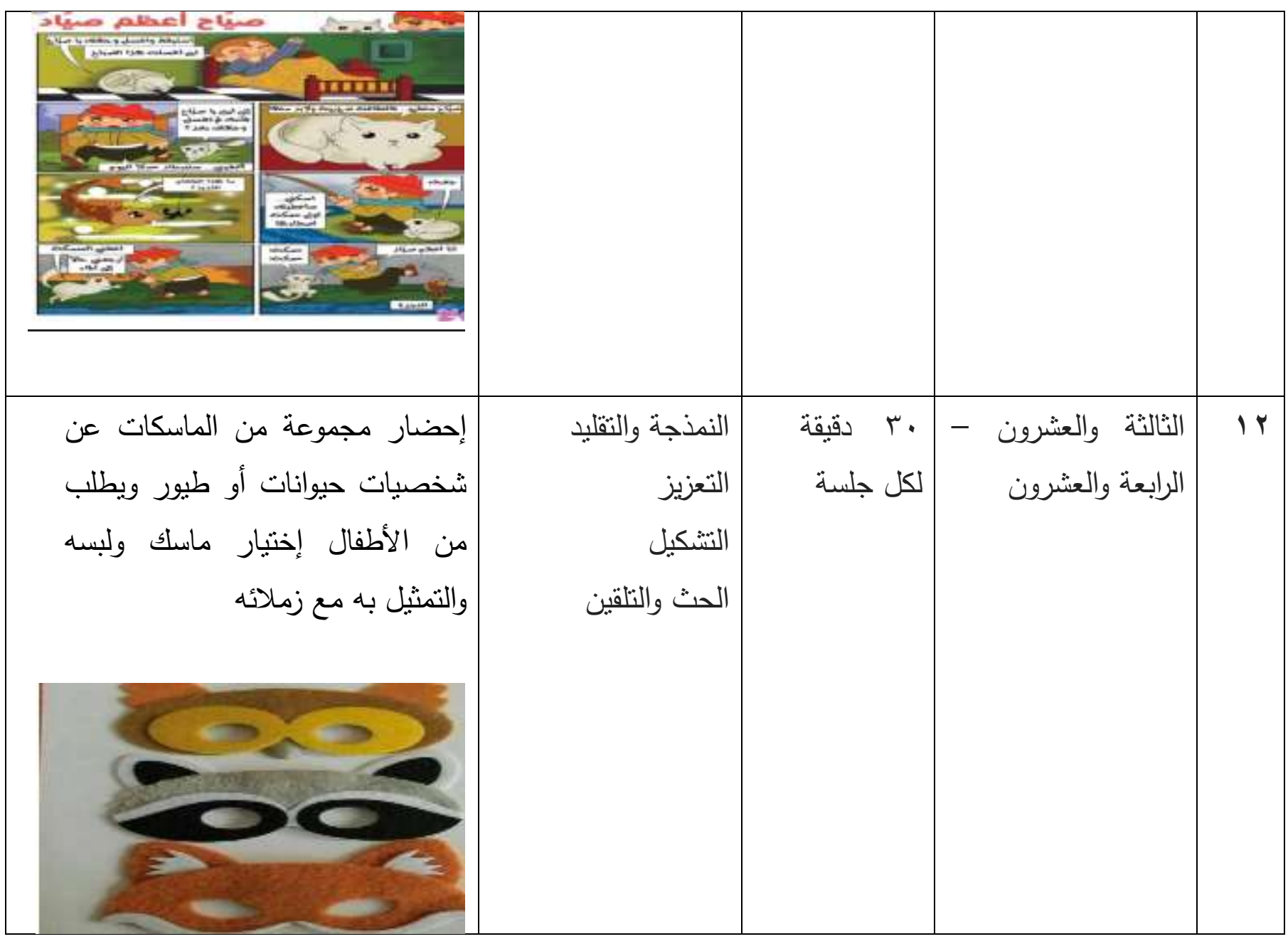

شكل بوضح إتجاه سبر البرنامج:

1- ألعاب تنمى لاى الطقل التعبير عن الذات

r- ألعاب تنمى لدى الطفل القدرة على التواصل وإلتفاعل

$$
\text { مع الأخرين }
$$

r- ألعاب تنمى لدى الطفل ثقته بذاته 
تم التكرار لجلسات اللبرنامج أثناء فترة التطبيق وذلك نتيجة لأعمار الأطفال الزمنية وكذلك لتحقيق فاعلية لجلسات البرنامج، كما تم مراعاة بعض الإعتبارات أثناء تطبيق البرنامج وهى كالتنالى

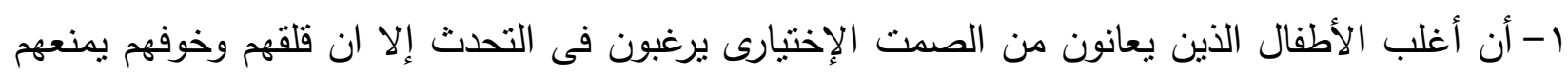

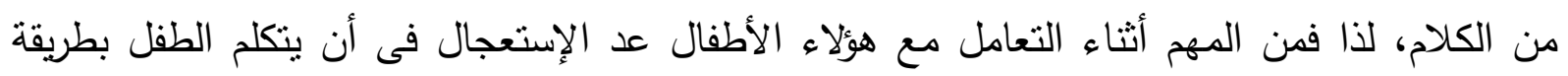

\section{صحيحة.}

r- إفهام الطفل بأن جميع من حوله يرغبون فى مساعدته ولكن سوف يتطلب ذلك وقت حتى يتحقق. r- تحديد المواقف التى تمتل صعوبة وضغط على الطفل وتجنبها وكذلك المواقف السهلة والمفضلة بالنسبة للطفل والبدأ منها. ع - إعداد بيئة أمنه للطفل بحيث لا يشعر بالخوف. ه- نتجيع الطفل على المشاركة وتعزيز مشاركته. צ- إتاحة الفرصة للطفل للتحدث دون توتر أو خوف من خلال اللعب والتمثيل الدرامى.

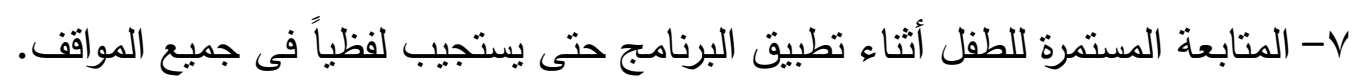
^- عدم الإصرار على التواصل البصرى من جانب الطفل أثناء الحديث معه. 9- عدم تقديم رشوة للطفل حتى يتكلم فهذا يزيد من قلق الطفل وتوتزه، وكذلك عدم معاقبته أذا رفض الكابل الكلام. • ا-إستخدام الدمى مع الطفل فهى من الوسائل المهمة فى مساعدة الطفل على الكلام دون خوف أو قلق فئ. صدق البرنامج: تم عرض البرنامج على مجموعة من المحكمين فى مجال علم النفس لتحكيم جلسات البرنامج وبلغت نسبة إتفاق

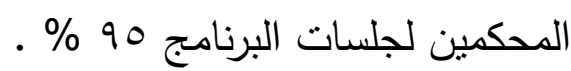
نتائج الاراسة ومناقشتها: نتيجة الفرض : وينص على ما يلي: 1-نوجد فروق دالة إحصائياً بين درجات أطفال المجموعة التجريبية من أطفال الروضة الذين طبق عليهم

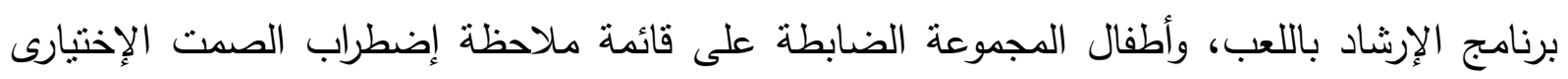
لصالح أطفال المجموعة التجريبية. ولإختبار صحة هذا الفرض نم حساب المنوسط الحسابي، والنسبة المئوية لخفض إضطراب الصمت الإختيارى عند أطفال الروضة، وقيمة (*ZZل للفروق بين أطفال مجموعتي البحث (تجريبية / ضابطة). 
جدول ( 1 ) (المتوسط الحسابي والنسب المئوية لخفض إضطراب الصمت الإختيارى وقيمة (Z) المحسوية للفروق بين أطفال مجموعتي البحث (تجريبية وضابطة)

\begin{tabular}{|c|c|c|c|c|c|c|c|}
\hline 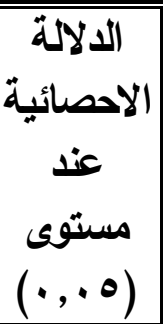 & قالمحسوية Z & المجي خفوعثين & الخفئة الإضية & الحستوسطي & العدد & المجموعة & \\
\hline \multirow{2}{*}{ إحصائيا } & \multirow{2}{*}{ ודוד," } & \multirow{2}{*}{$\% \vee v, r q$} & $\% 90,91$ & $19, r$ & $\varepsilon$ & تجريبية & عبارات القائمة \\
\hline & & & $\%$ \% $\varepsilon, O r$ & $r Y, \Lambda$ & $\varepsilon$ & ضابطة & . 7 درجة \\
\hline
\end{tabular}

r- يتضح من الجدول السابق ما يلي:

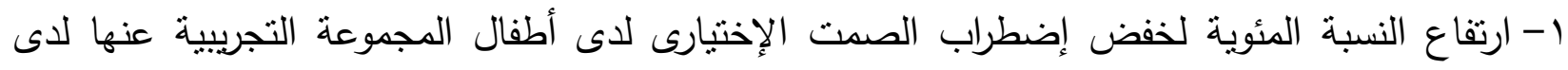

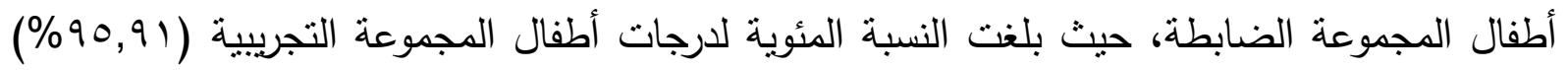

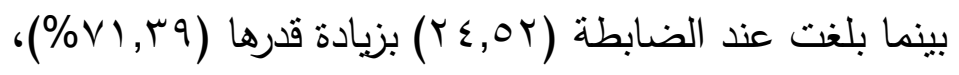

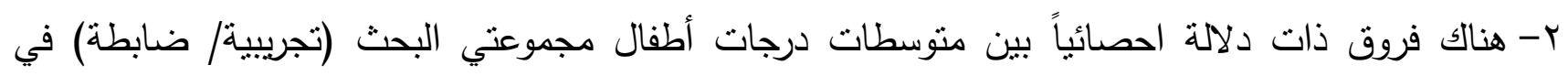

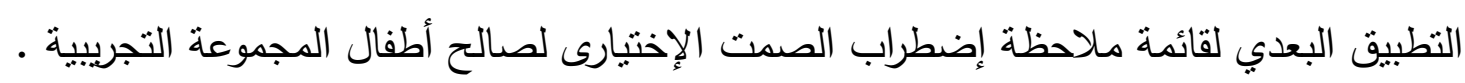

مناقثة نتيجة الفرض : تتضح من البيانات السابقة تأكيد صحة الفرض من حيث وجود فروق دالة إحصائياً بين درجات أطفال المجموعة

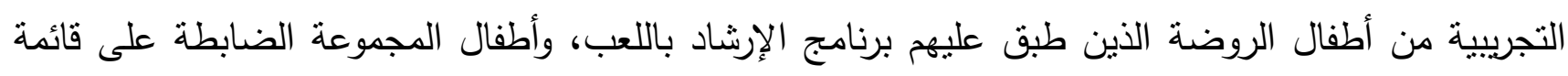
ملاحظة إضطراب الصدت الإختيارى لصالح أطفال المجموعة التجريبية.

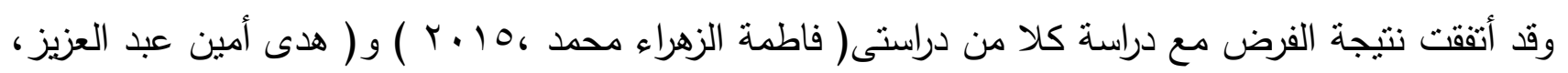

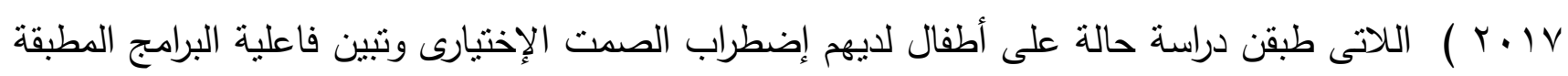

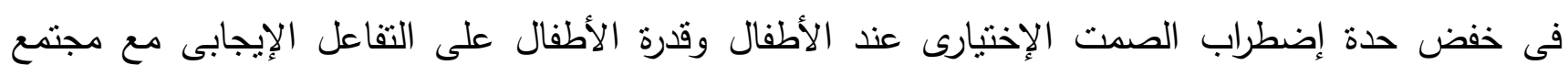
الأقران.

كذلك أتفقت نتيجة الدراسة مع دراسة نيوبرى ( Newberry, 2014 ) والتى أسفرت عن تحسن ملحوظ في اللغة

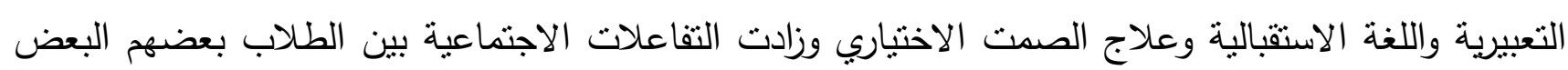

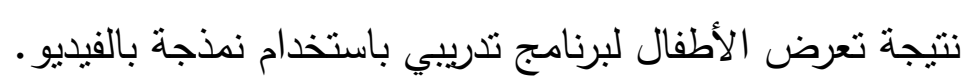
كما أنفقت مع دراسة هاروود ( Harwood and Bork, 2011 ) والتى أسفرت نتائجها عن فعالية البرنامج التدريبي في علاج الصمت الاختياري وزيادة النواصل اللغوي لدى الأطفال.

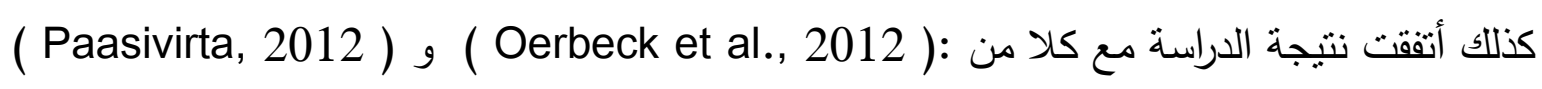


و (Ooi et al., 2012 من حيث فعالية برامج العلاج السلوكى في خفض إضطراب الصمت الاختياري لدى

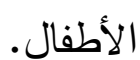
أيضا أتفقت نتيجة الدراسة مع نتيجة دراسة كلا من لانج وأخرون ( Lang et al., 2011 ) و كلاين وأخرون

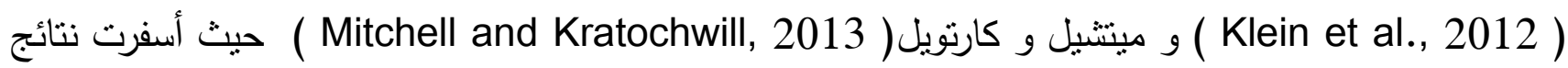
الدراسات عن فاعلية برامج العلاج السلوكى فى خفض إضطراب الصمت الإختبارى فى المواقف الإجتماعية ، وتتمية الكفاءة اللغوية لدى الأطفال. كما أتصف البرنامج المقترح بدرجة مناسبة من الفاعلية في خفض إضطراب الصمت الإختيارى لدى أطفال الروضة من (ع-7) سنوات. جدول ( V ) المتوسط الحسابي والانحراف المعياري وحجم التأثثر التجريبي للمجموعتين التجريبية والضابطة في التطبيق البعدي لقائمة ملاحظة إضطراب الصمت الإختيارى.

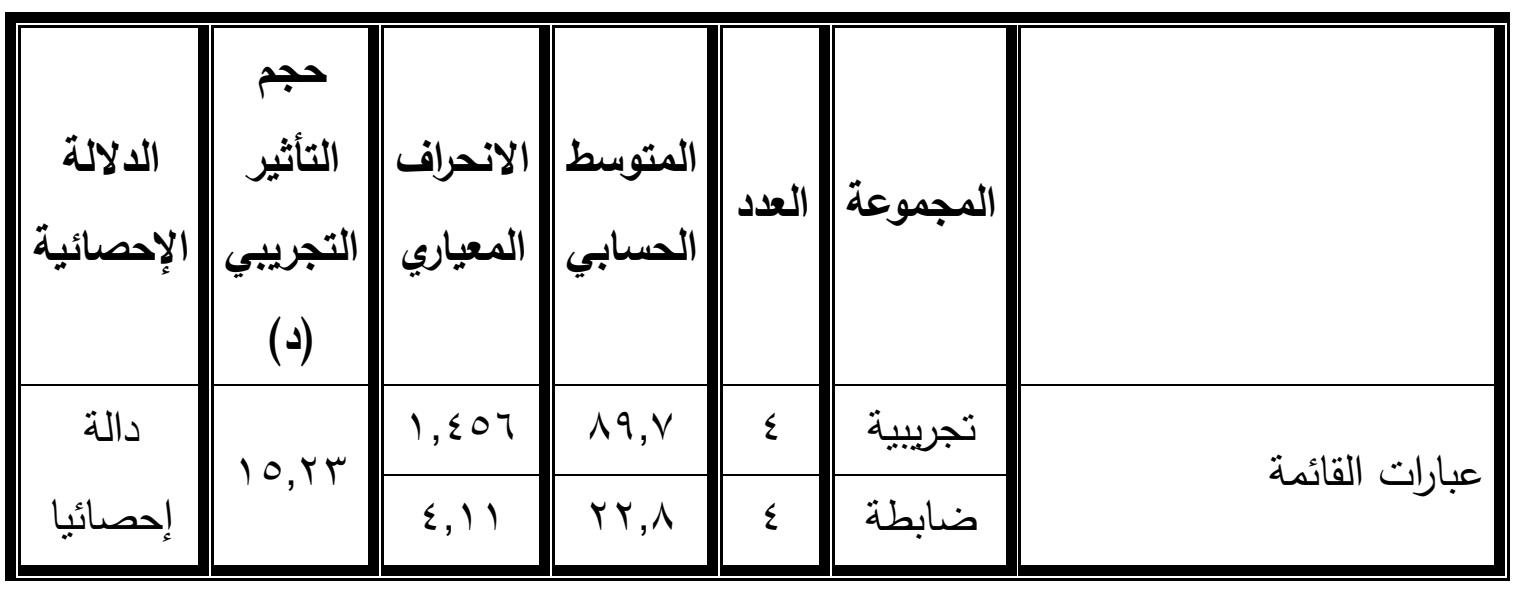

إذا كان (د) = r, · · فإن ذلك يدل على حجم صغير للأثز.

إذا كان (د) = 0, • فإن ذلك يدل على حجم متوسط للأثر.

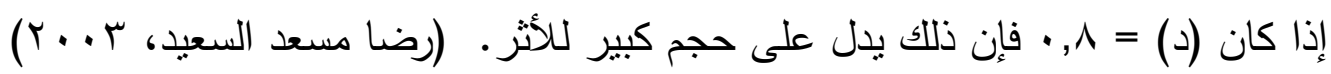

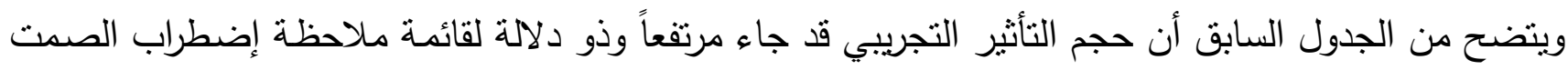

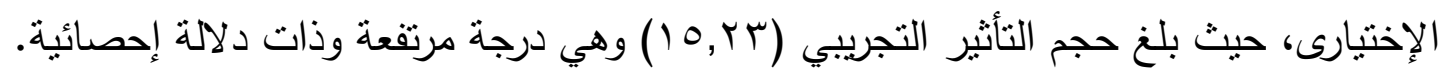

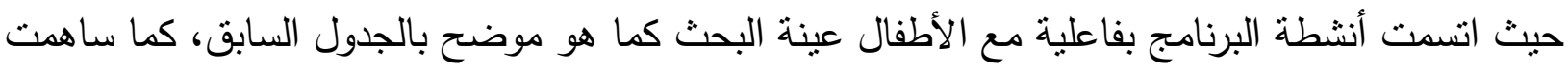
أنشطة البرنامج فى زيادة قدرة الأطفال على التفاعل وتحسين التواصل البصرى واللفظى لديهم، أيضا ساهمت أنشطة البرنامج فى تتمية النقة بالنفس وتدعيم الذات، تتمية قدرة الأطفال على التعبير الكلامي ، كذللك تدريب الأطفال على التواصل البصري والحوار والمناقثة، وتتمية قدرة الأطفال على الاندماج في الععل، كذلك تتمية قدرة الأطفال على التعبير عن ذاتهم وعن مشاعرهم وتتمية قدرتهم على المشاركة في الأنشطة التى تقدها المعلمة 
، وذلك لأن البرنامج مناسب لخصائص نمو الأطفال ويشبع حاجة الطفل إلى اللعب بالإضافة أنه قدم اللعب فى شكل نثاط موجه للطفل.

كما أن البرنامج تدرج فى خفض إضطراب الصمت الإختيارى عند الأطفال من ( ع-7 ) سنوات فهو بدأ بمساعدة الطفل فى الإسترخاء والتعبير عن الذات، ثم مساعدة الطفل فى تتمية ثقته بذاته، وأخيراً تتمية قدرته على الثى التواصل والتفاعل مع الأخرين.

كما كان للعب دور كبير فى خفض إضطراب الصدت الإختبارى عند الأطفال، حيث لاحظت الباحثة عدم

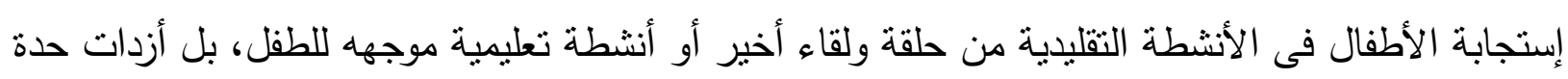
الإضطراب عند الأطفال، ولكن مع تقديم جلسات اللعب للأطفال عينة البحث ( التجريبية ) بدأ بظهر تحسن ملحوظ فى إستجابة الأطفال والتخفيف من شدة القلق لديهم وظهرت فروق واضحة مع المجموعة التجريبية مقارنة بالمجموعة الضابطة.

\section{توصيات الاراسة:}

1-الاستفادة من نتائج الدراسة الحالية في الإهتمام بالأطفال المصابين بإضطراب الصدت الإختبارى ومحاولة التذخل المبكر معهم. ז- العمل على تعديل مناهج رياض الأطفال والطفولة المبكرة بحيث يقدم من خلال اللعب ويراعى خصائص نمو الأطفال. ب- ضرورة تدريب المعلمات على الكثف المبكر عن حالات الصمت الإختيارى عند الأطفال ، والتدريب على كيفية التخل معهم.

البحوث المقترحة:

1-فاعلية برنامج الإرشاد باللعب فى خفض إضطراب الصمت الإختبارى لاى الأطفال ذوى صعوبات التعلم.

r- دور اللعب فى النمو اللغوى والعقلى لطفل الروضة.

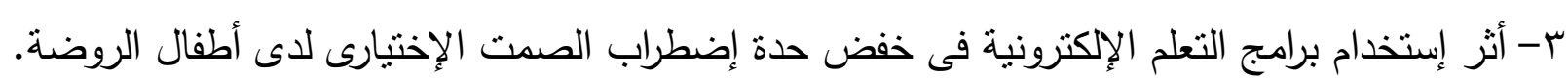




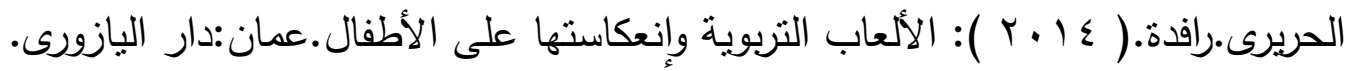

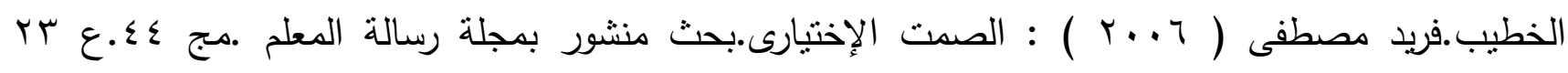
•مصر :وزارة التربية والتعليم. مصن.

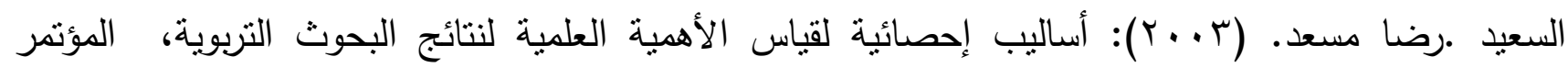

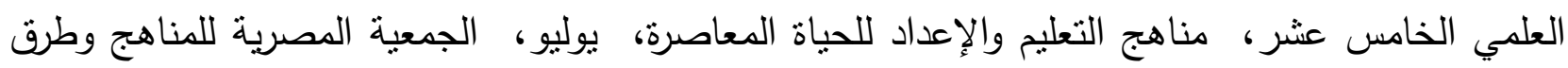
التدربس.

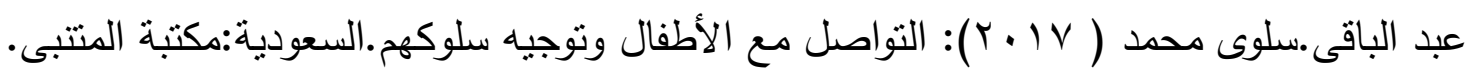

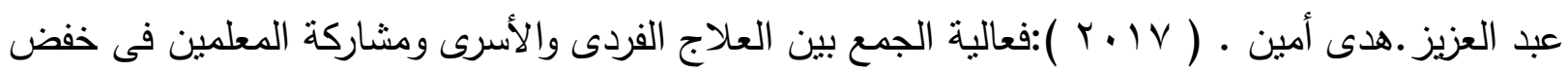
حدة الصمت الإختيارى ( دراسة حالة)،بحث منشور بمجلة كلية الدراسات الإنسانية، مصر • ع يونية .

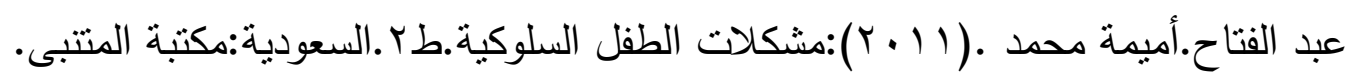
عبد الهادي، نبيل .( ع . . (ب).سيكولوجية اللعب وأثرها في تعلم الأطفال .الأردن :دار وائل للنشر . العنانى.حنان عبد الحميد ( ع ( r):اللعب عند الأطفال الأسس النظرية والتطبيقية.ط9.الأردن : دار الفكر قناوى.هدى محمد ( ع ا ـ r ) ): الطفل وألعاب الروضة.السعودية:مكتبة المتتبى. كمال أمين عبد العاطي. منى ( ؟ ( ب): فعالية العلاج باللعب في الحد من بعض مشكلات الانضباط السلوكي لدى الأطفال ذوي الإعاقة العقلية البسيطة، رسالة دكتوراه، كلية التربية، جامعة بني سويف.

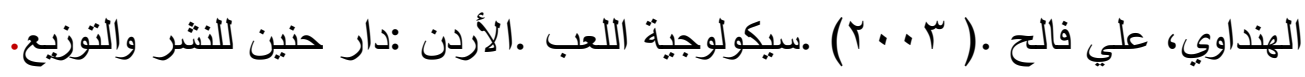

Ale,C.M. , Mann,A., Menzel,J., Storch, E., Adam B., Lewin, A.B.( 2013). Two Cases of Early Childhood Selective Mutism: Variations and Treatment Complexities .Clinical Case Studies, 12(4), 278-290.

American Psychiatric Association (2013). Diagnostic and statistical manual of mental disorders. (4th ed.), Text Revision). Washington, DC: Author.

Bergman, R. L., Gonzalez, A., Piacentini, J., \& Keller, M. (2013) Integrated Behavior Therapy for Selective Mutism: A randomized controlled pilot study, 51 (10) , 680705.

Child Mind Institute: (2016): Teachers Guide to Selective Mutism.p2 
Christopher A. Kearney (2010). Helping Children with Selective Mutism and Their parents :Oxford University Press,p.5011

Carbone, D., Schmidt, A., Cunningham, C., McHolm, E., Edison, S., Pierre, J.\& Boyle, M. (2010). Behavioral and Socio-emotional Functioning in Children with Selective Mutism: A Comparison with Anxious and Typically Developing Children Across Multiple Informants. Journal of Abnormal Child Psychology. Nov, 38 (8), 1057-1067.

Davidson, M. (2012).Selective mutism: Exploring the knowledge and needs of teachers, Psy. D, Rutgers University; Graduate School of Applied and Professional Psychology, p. 126

Diliberto, R. . (2014). Oppositional and anxiety behavior profiles in a clinical sample of youth with selective mutism, University of Nevada, Las Vegas, M.S. University of Nevada, Las Vegas. p153.

Eysenk,, M., (2000). Psychology, A Student's Handbook. Psychology Press Ltd Publishers. UK.

Hung,S.L., Spencer,M.S., Dronamraju,R.( 2012). Selective Mutism: Practice and Intervention Strategies for Children. Children and Schools, 34 (4): 222-230. doi: $10.1093 / \mathrm{c} \mathrm{s} / \mathrm{cds} 006$

Harwood, D.\& Bork, P. (2011). Meeting educators where they are: Professional development to address selective mutism. Canadian Journal of Education, 34 (3), 136-152.

Justin, A. B. (2015).Fluoxetine for the treatment of selective mutism with elevated social anxiety symptoms: A nonconcurrent multiple baseline design across five cases, Ph.D. School Psychology, Michigan State University.

Kearney, C.A (2010). Helping children with selective mutism and their Parents, A Guide for School-Based Professionals. Oxford University Press. 
Kehle, T. J., Bray, M. A., Byer-alcorace, G. F., Theodore, L. A. and Kovac, L. M. (2012). Augmented self-modeling as an intervention for selective mutism.

Psychology in the Schools. 49, (1), 93-103. doi:10.1002/pits.21589

Kotrba, A. (2015).Selective Mutism: An Assessment and Intervention Guide for

Therapists, Educators \& Parents. PESI publishing \& Media.

Klein, E. R.., Armstrong, S. L.\& Shipon. B (2012).Assessing spoken language competence in children with selective mutism: Using parents as test presenters, Communication Disorders Quarterly, 34 (3),184-195.

Kristin K. Meany-Walen, M.A. (2010): Alderian play therapy: Effectiveness on Disruptive behaviors of early elementary-aged children. Unpublished Doctor Dissertation, Doctor Degree of Philosophy University of North Texas.

Lang, R., Regester, A., Mulloy, A., Rispoli, M\& Botout, A. (2011). Behavioral intervention to treat selective mutism across multiple social situations and community settings, Journal of Applied Behavior Analysis,44, 3, 623-628

Mitchell, A. \& Kratochwill, T,. (2013).Treatment of selective mutism: applications in the clinic and school through conjoint consultation, Journal of Educational \& Psychological Consultation, 23 (1) , 30-36.

Muris, P., Ollendick, T.H. (2015).Children who are Anxious in Silence: A Review on Selective Mutism, the New Anxiety Disorder in DSM-5. Child Family Psychology Reviews, 18,151-169 DOI 10.1007/s10567-015-0181-y

Newberry ,P. D. (2014). Efficacy of video modeling for treatment of selective mutism in children, University of South Carolina, ProQuest, UMI Dissertations Publishing. 149-179.

Ooi, Y. , Raja, M., Sung, S. , Fung, D. , Koh, J. , et al. (2012) Application of a webbased cognitive-behavioural therapy programme for the treatment of selective mutism in Singapore: a case series study. Singapore medical journal, 53 (7) , 446450. 
Oerbeck, B. , Johansen, J., Lundahl, K. \& Kristensen, H. (2012). Selective mutism: A home-and kindergarten-based intervention for children 3-5 Years: A pilot study, Clinical Child Psychology \& Psychiatry, 17 (3) , 370- 383.

Oerbeck B, Manassis K, Overgaard KR, Kristensen H. Selective mutism.( 2016). In Rey JM (ed), IACAPAP e-Textbook of Child and Adolescent Mental Health. Geneva: International Association for Child and Adolescent Psychiatry and Allied Professions.

Paasivirta, M. (2012). Effects of a brief behavioral training program for teachers of children with selective mutism, Hofstra University, ProQuest, UMI Dissertations Publishing.

Shipon,E.(2013). A GUIDE to Helping Parents, Educators and Treatment professionals Understand Selective Mutism as a Social Communication Anxiety Disorder; Smart Center,p1

Shipon.E \& Ann.C (2015) : Selective Mutism: Identification of Subtypes and Implications for Treatment, Journal of Education and Human Development, Vol. 4, No. 1 ,

Steinhausen, H., Wachter, M., Laimbock, K., \& Metzke, C. (2006). A long-term outcome study of selective mutism in childhood. Journal of Psychology and Psychiatry, 47 (7) , 751-756.

Young, B. J., Bunnell, B. E. \& Beidel, D.C. (2012). Evaluation of children with selective mutism and social phobia: A comparison of psychological and psycho physiological Arousal, Behavior Modification, 36, (4) , 525-544. 